\title{
HLA Allele-specific Quantitative Profiling of Type 1 Diabetic B Lymphocyte Immunopeptidome
}

\section{Putty-Reddy Sudhir, Tai-Du Lin, Qibin Zhang*}

\section{Figure captions}

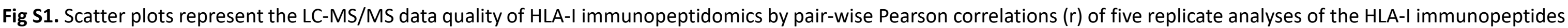
enriched from 2676 (T1D) and 2675 (HC) B cells.

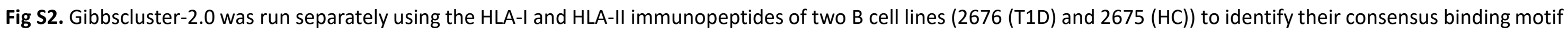



Fig S3.

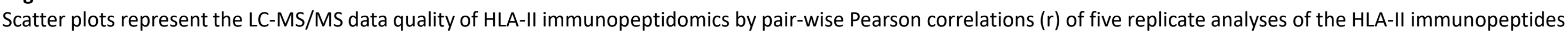
enriched from 2676 (T1D) and 2675 (HC) B cells.

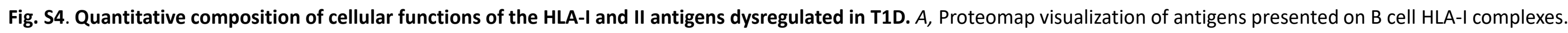

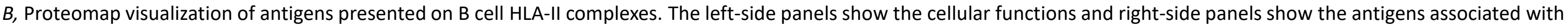

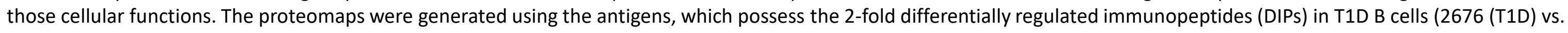

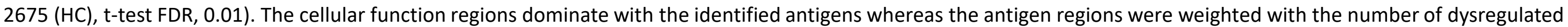
immunopeptides in T1D.

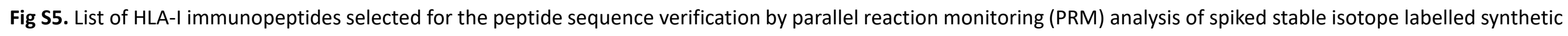
peptides.


peptides and MixMHC2pred results.

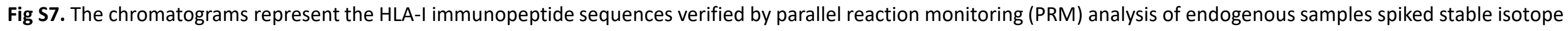
labelled synthetic peptides. The b or y ions coeluted or interfered with other ions were excluded from the chromatograms. 
Fig S8. The chromatograms represent the HLA-II immunopeptide sequences verified by parallel reaction monitoring (PRM) analysis of endogenous samples spiked stable isotope labelled synthetic peptides. The b or y ions coeluted or interfered with other ions were excluded from the chromatograms. For some peptides, the HLA-II endogenous peptides identified in two cell lines experiment were compared with SIS peptide fragments by Mirror Plots, which were created using SigmaPlot.

Fig S9. Immunopeptides enriched from six additional B cell lines (2679 (HC), 2812 (HC), 2741 (HC), 2678 (T1D), 2765 (T1D), and 3027 (T1D)) were analyzed in two replicates (TR1 and TR2) by LC-MS/MS. Figure S8A shows the number of HLA-I (left panel) and HLA-II (right panel) immunopeptides detected in six B cell lines. Figure S8B represents the length of the HLA-I (left panel) and HLA-II (right panel) immunopeptides identified in six B cell lines listed in Figure 8AB.

Fig S10. HLA-I Immunopeptides identified in six B cell lines (2679 (HC), 2812 (HC), 2741 (HC), 2678 (T1D), 2765 (T1D), and 3027 (T1D)) were assigned to HLA allotypes based on their binding affinities to HLA-I alleles (Figure S9A). HLA-II Immunopeptides identified in six B cell lines were assigned to the different HLA allotypes based on their binding affinities to HLAII alleles (Figure S9B). The binding affinities were predicted using NetMHCpan 4.1 and NetMHCllpan 4.0 in case of HLA-I and HLA-II, respectively.

Fig S11. Gibbscluster-2.0 was run separately using the HLA-I immunopeptides of each of the six B cell lines (2679 (HC), 2812 (HC), 2741 (HC), 2678 (T1D), 2765 (T1D), and 3027 (T1D)) to identify their consensus binding motif sequences. The identified motifs were verified with the naturally presented ligand sequences of HLA alleles obtained from Motif viewer.

Fig S12. Gibbscluster-2.0 was run separately using the HLA-II immunopeptides list of each of the six B cell lines (2679 (HC), 2812 (HC), 2741 (HC), 2678 (T1D), 2765 (T1D), and 3027 (T1D)) to identify their consensus binding motif sequences. The identified motifs were verified with the naturally presented ligand sequences of HLA alleles obtained from Motif viewer.

Fig S13. LC-MS/MS analysis of HLA-I and HLA-II immunopeptides of T1D and healthy B cells resulted in identification of the peptides that are part of HLA molecules. These peptides were listed along with their information reported by previous studies in IEDB database. 
Figures

Fig. S1

Fig. S2

Fig. S3

Fig. S4

Fig. S5

Fig. 56

Fig. 57

Fig. 58

Fig. 59

Fig. S10

Fig. S11

Fig. S12

Fig. S13
Page No.

04

05

06

07

08

09

10-37

38-67

68

69

70

71

72

3 


\section{Fig. $\$ 1$}

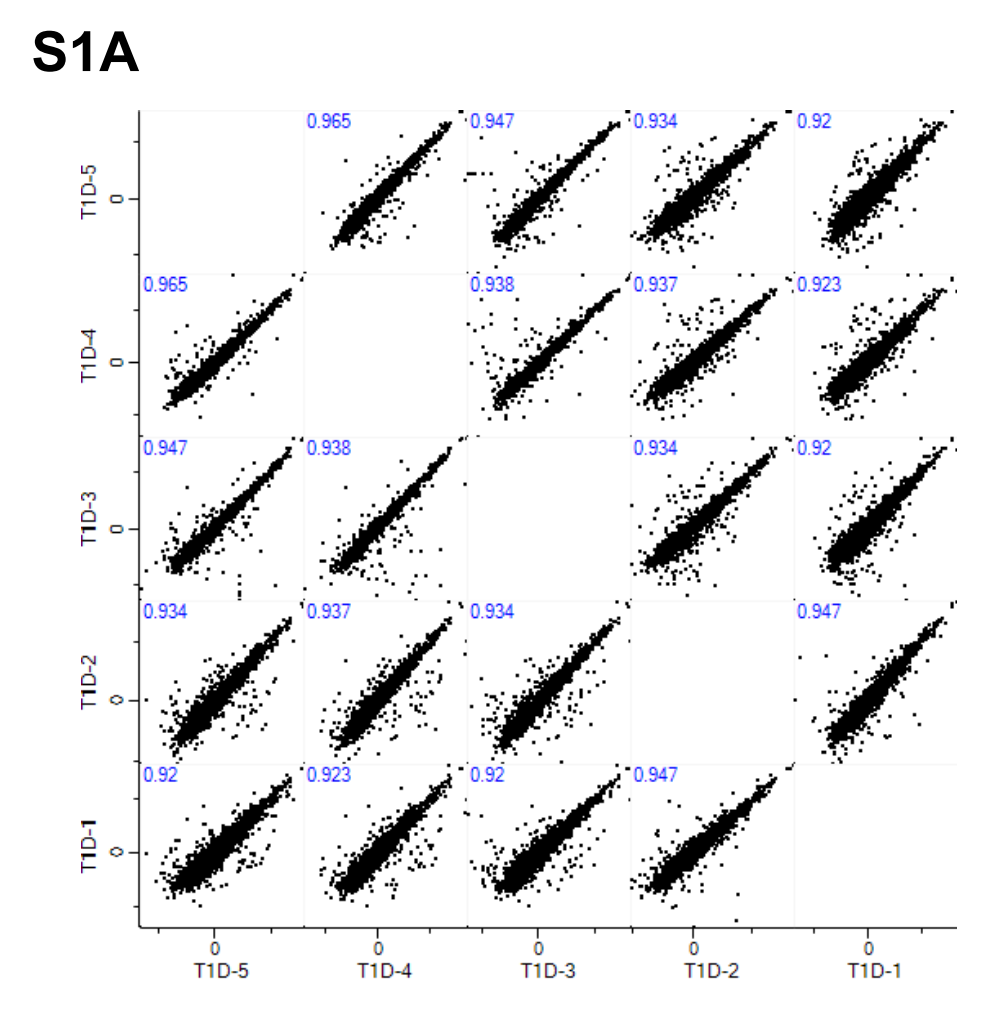

Correlation between five T1D replicates $(r)=0.92-0.965$

\section{S1B}

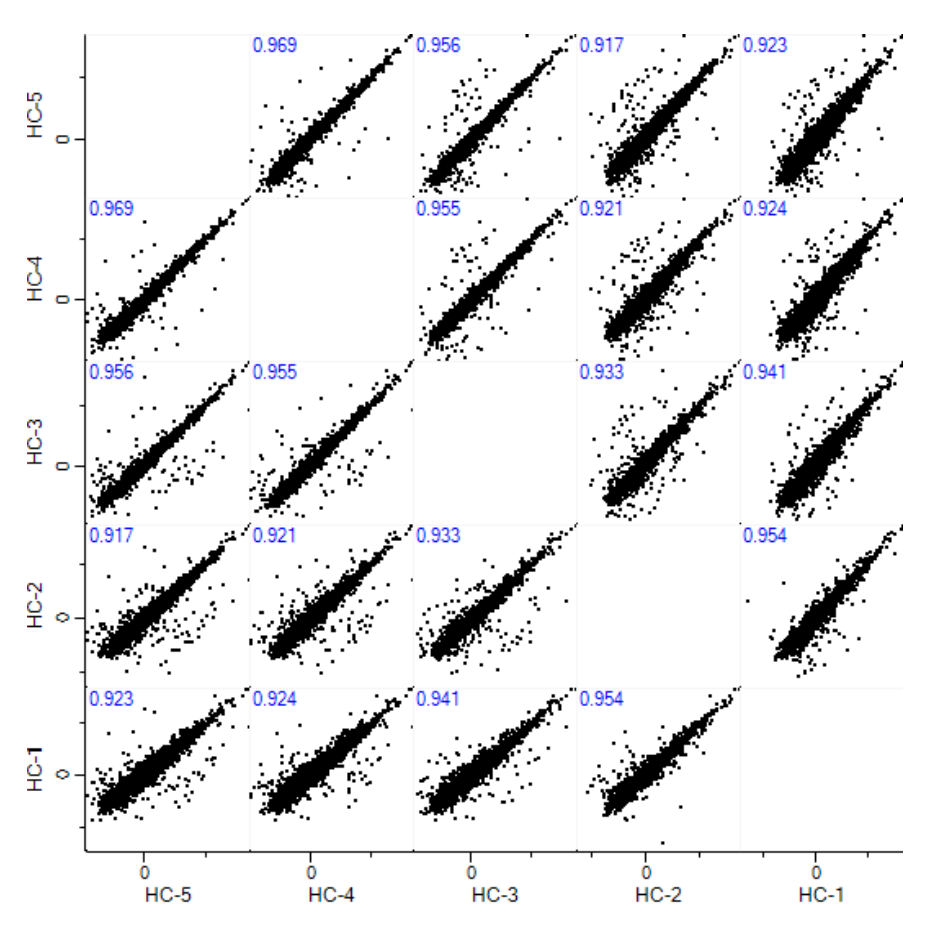

Correlation between five $\mathrm{HC}$ replicates $(r)=0.917-0.969$

\section{S1C}

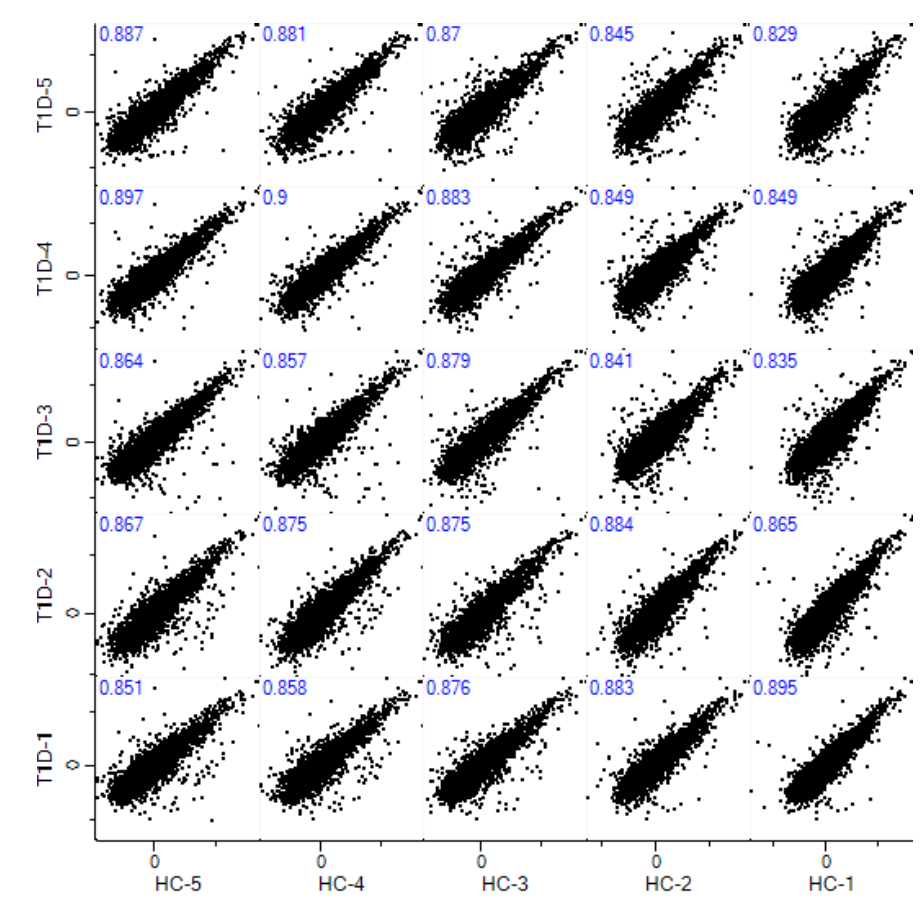

Correlation between five T1D and five $\mathrm{HC}$ replicates $(r)=0.829-0.9$ 
Fig. S2

HLA-I
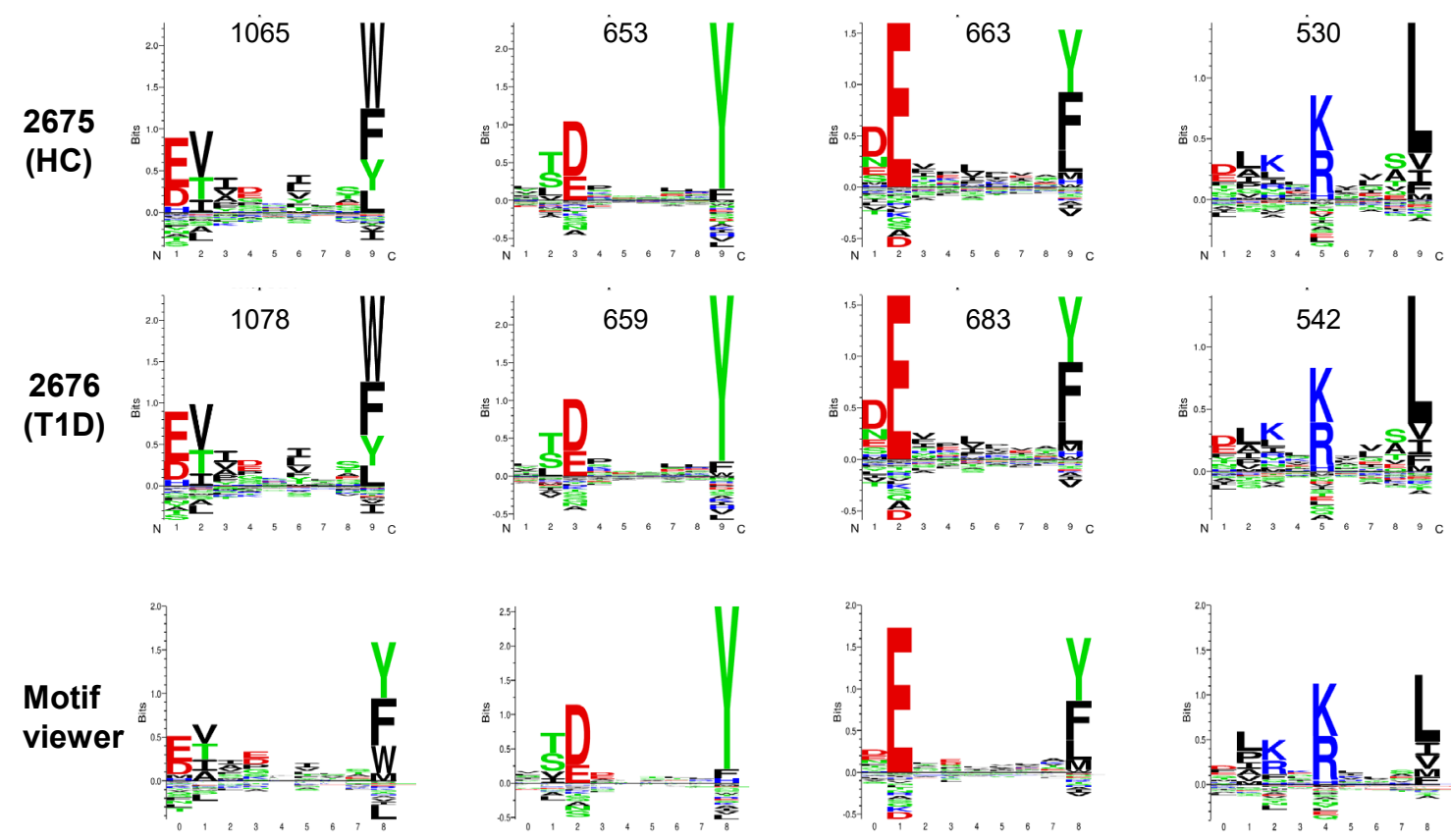

HLA-A*25:01



HLA-A*01:01

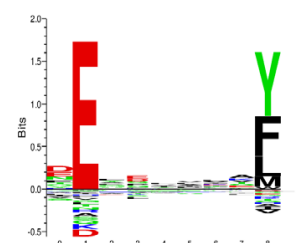

HLA-B ${ }^{* 18: 01}$


HLA-B*08:01

\section{HLA-II}






\section{Fig. S3}

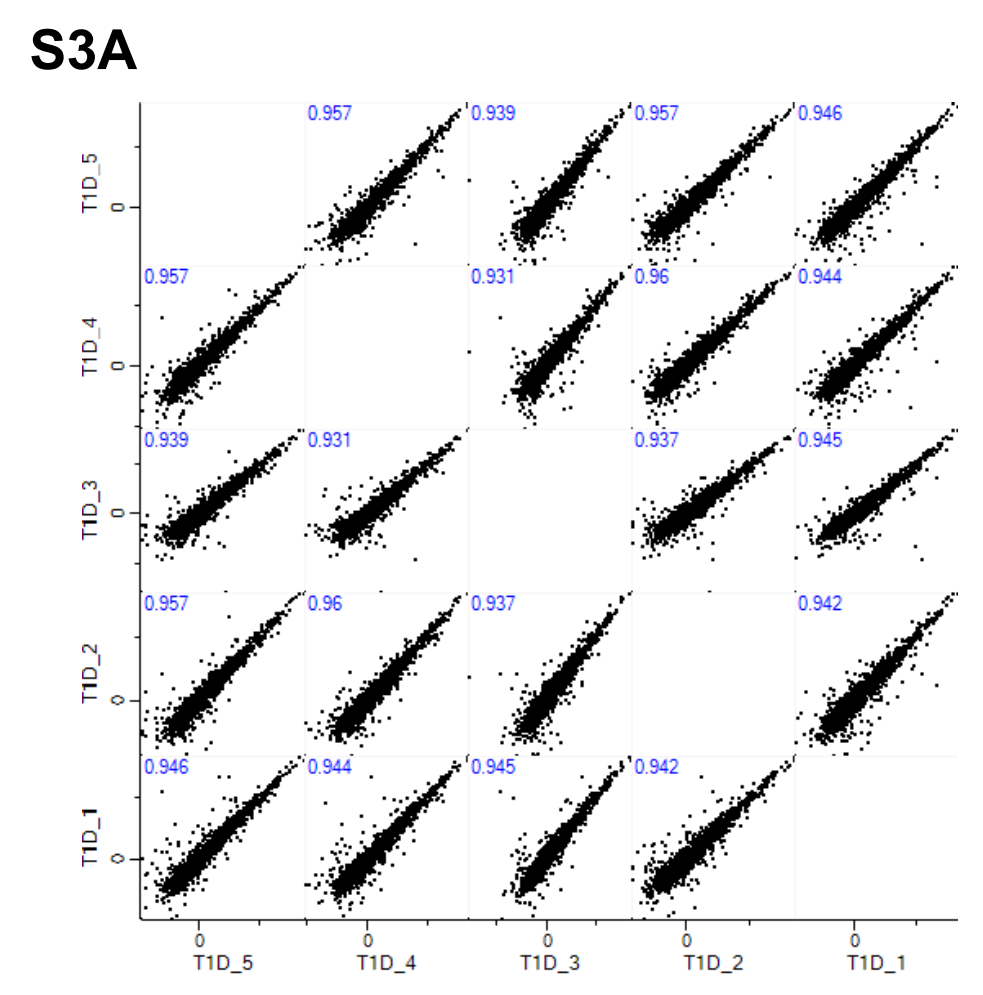

Correlation between five T1D replicates $(r)=0.931-0.96$

\section{S3B}

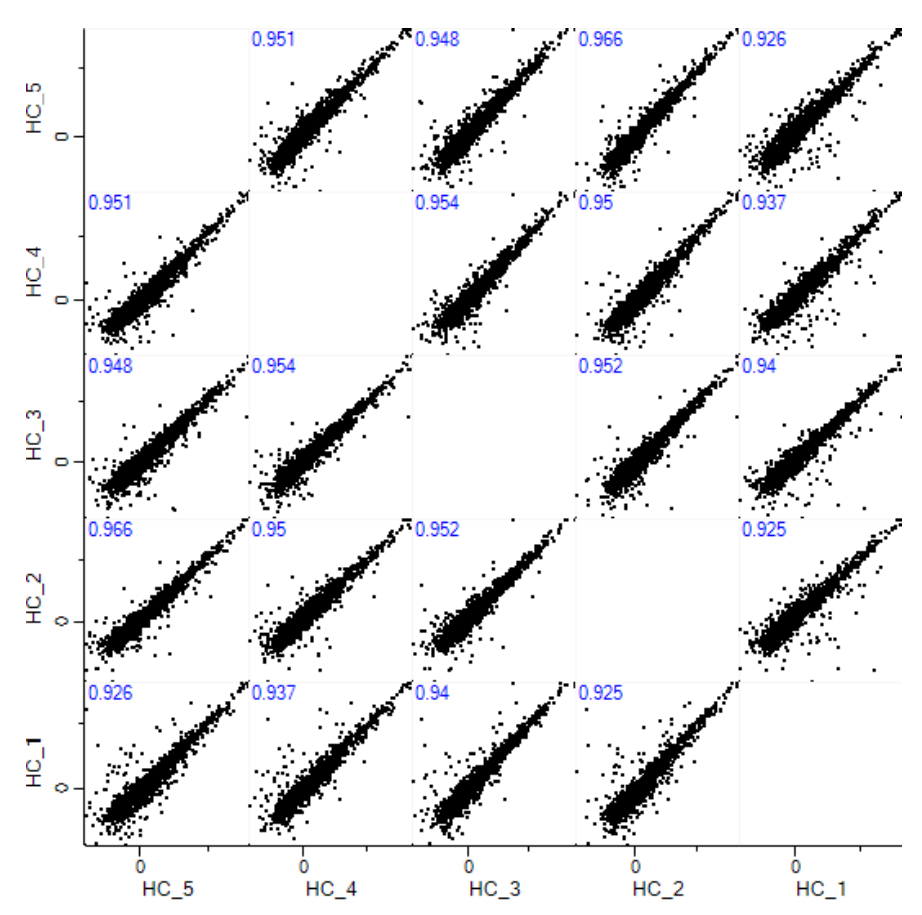

Correlation between five $\mathrm{HC}$ replicates $(r)=0.925-0.966$

\section{S3C}

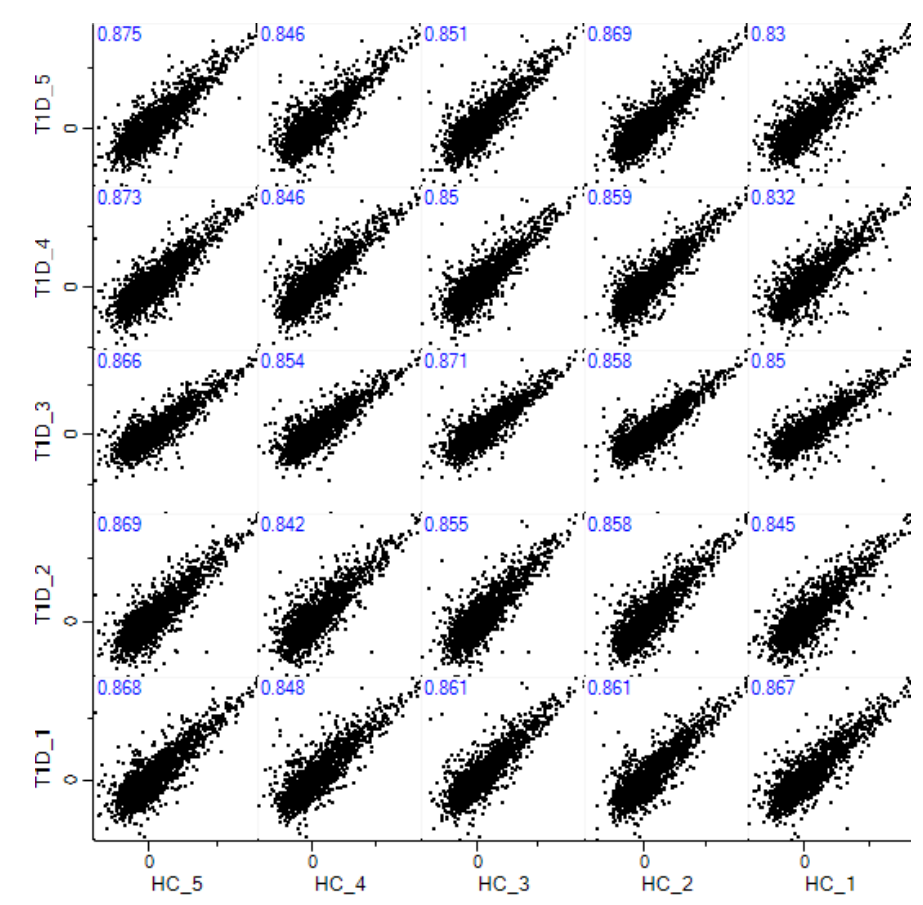

Correlation between five T1D and five $\mathrm{HC}$ replicates $(r)=0.83-0.875$ 
A HLA-I antigens

Fig. S4
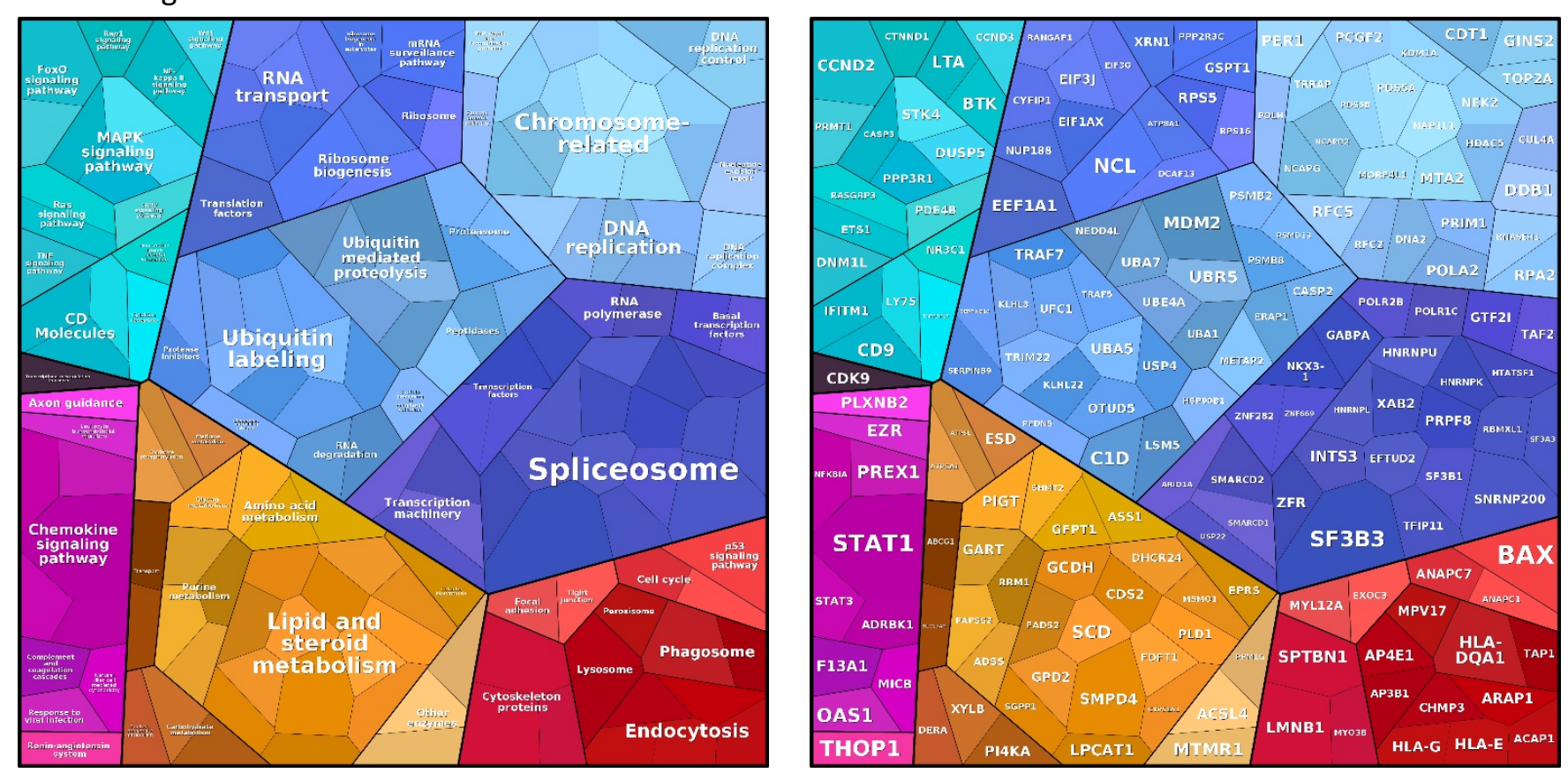

B HLA-II antigens

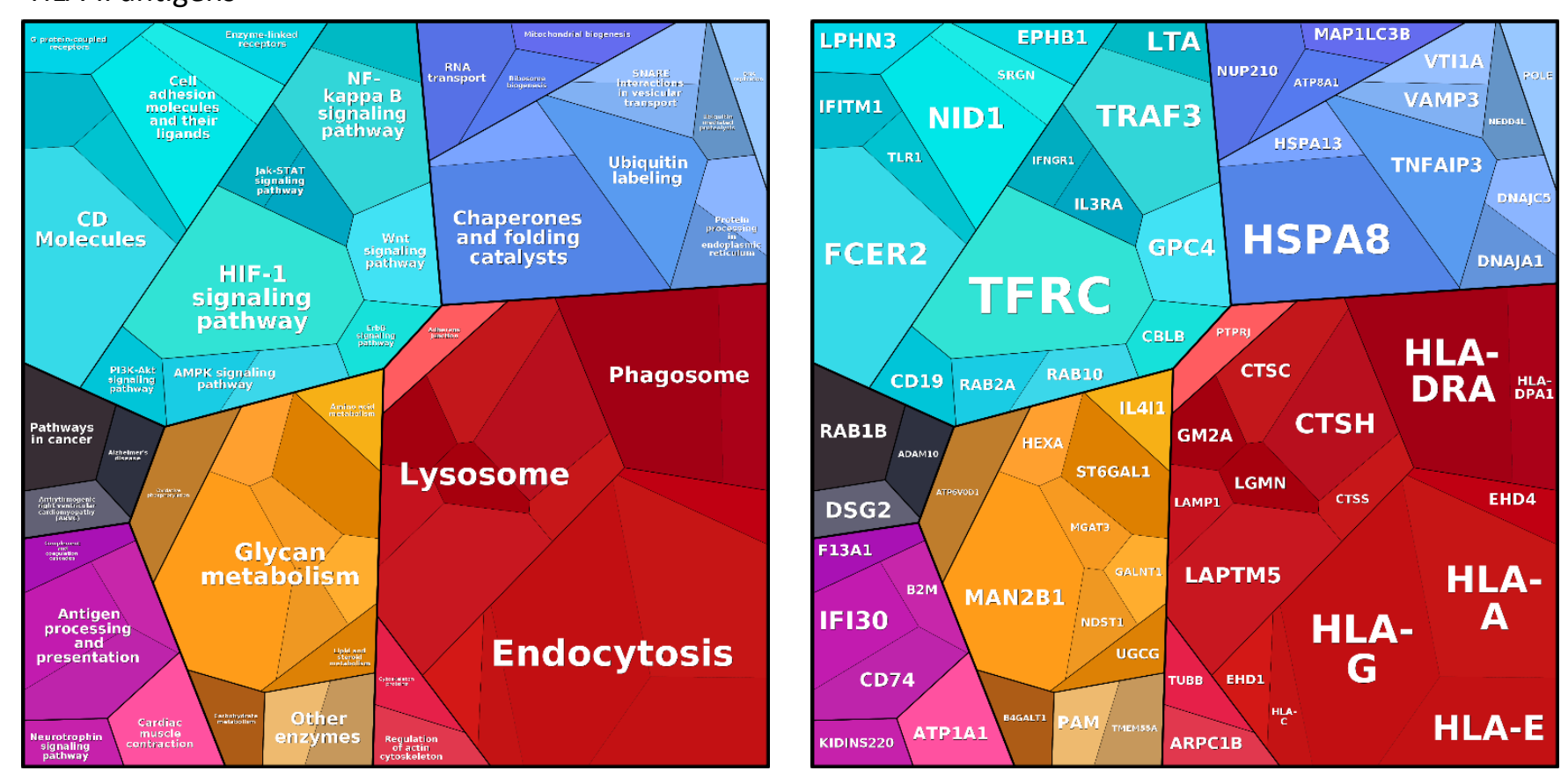




\section{Fig. S5}

\begin{tabular}{|c|c|c|c|c|c|c|c|c|c|c|c|}
\hline \multirow[b]{2}{*}{ No. } & \multirow[b]{2}{*}{ Uniprot ID } & \multirow[b]{2}{*}{$\begin{array}{l}\text { Protein } \\
\text { symbol }\end{array}$} & \multirow[b]{2}{*}{ Protein name } & \multirow[b]{2}{*}{ Sequence } & \multirow[b]{2}{*}{ Length } & \multirow[b]{2}{*}{$\begin{array}{c}\text { Log2 Fold } \\
\text { change }\end{array}$} & \multirow[b]{2}{*}{$\begin{array}{l}\text { HLA } \\
\text { class }\end{array}$} & \multirow[b]{2}{*}{ HLA alleles } & \multicolumn{3}{|c|}{ Criteria } \\
\hline & & & & & & & & & $\begin{array}{l}\text { Significant } \\
\text { diffierence }\end{array}$ & $\begin{array}{c}\text { Biological } \\
\text { significance } \\
*\end{array}$ & $\begin{array}{c}\text { ID in T1D } \\
\text { only }\end{array}$ \\
\hline 1 & Q8IV61 & RASGRP3 & Ras guanyl-releasing protein 3 & EVITKFINV & 9 & 2.11 & $\mathrm{I}$ & HLA-B08:01 & yes & $\&$ & \\
\hline 2 & Q9H1A4 & ANAPC1 & Anaphase-promoting complex subunit 1 & NTDPSIVMTY & 10 & 1.91 & $\mathrm{I}$ & HLA-A01:01 & yes & \&\# & \\
\hline 3 & Q02223 & TNFRSF17 & Tumor necrosis factor receptor superfamily member 17 & DEIILPRGLEY & 11 & 1.85 & $\mathrm{I}$ & HLA-B18:01 & yes & $\&$ & \\
\hline 4 & Q96G74 & OTUD5 & OTU domain-containing protein 5 & NEDEPIRVSY & 10 & 1.66 & 1 & HLA-B18:01 & yes & $\&$ & \\
\hline 5 & P01374 & LTA & Lymphotoxin-alpha & HEVQLFSSQY & 10 & 1.65 & 1 & HLA-B18:01 & yes & $\&$ & \\
\hline 6 & P68104 & EEF1A1 & Elongation factor 1-alpha 1 & ESFSDYPPLGRF & 12 & 1.59 & 1 & HLA-A01:01 & yes & $\&$ & \\
\hline 7 & Q9UJX3 & ANAPC7 & Anaphase-promoting complex subunit 7 & LLGSLADLY & 9 & 1.59 & $\mathrm{I}$ & HLA-A01:01 & yes & $\& \#$ & \\
\hline 8 & Q03518 & TAP1 & Antigen peptide transporter 1 & TALPRIFSL & 9 & 1.58 & 1 & HLA-C12:03 & yes & $\& \#$ & \\
\hline 9 & P42575 & CASP2 & Caspase-2 & DMLVKVNAL & 9 & 1.56 & $\mathrm{I}$ & HLA-B08:01 & yes & $\&$ & \\
\hline 10 & P28062 & PSMB8 & Proteasome subunit beta type- 8 & VSDLLHQY & 8 & 1.49 & $\mathrm{I}$ & HLA-A01:01 & yes & $\& \#$ & \\
\hline 11 & Q7L576 & CYFIP1 & Cytoplasmic FMR1-interacting protein 1 & EVISGYEEL & 9 & 1.45 & $\mathrm{I}$ & HLA-A25:01 & yes & $\&$ & \\
\hline 12 & P42574 & CASP3 & Caspase-3 & STAPGYYSW & 9 & 1.28 & 1 & HLA-C12:03 & yes & $\&$ & \\
\hline 13 & Q9NZ08 & ERAP1 & Endoplasmic reticulum aminopeptidase 1 & ETIEENIGW & 9 & 1.27 & 1 & HLA-A25:01 & yes & \&\# & \\
\hline 14 & P40305 & IFI27 & Interferon alpha-inducible protein 27 , mitochondrial & AAVPMVLSA & 9 & 1.27 & $\mathrm{I}$ & HLA-C12:03 & yes & $\&$ & \\
\hline 15 & Q01518 & CAP1 & Adenylyl cyclase-associated protein 1 & NEFPVPEQF & 9 & 1.27 & 1 & HLA-B18:01 & yes & $\&$ & \\
\hline 16 & P42224 & STAT1 & Signal transducer and activator of transcription 1-alpha/beta & DSFPMEIRQY & 10 & 1.21 & $\mathrm{I}$ & HLA-A01:01 & yes & $\&$ & \\
\hline 17 & P41218 & MNDA & Myeloid cell nuclear differentiation antigen & EVPNRIIEI & 9 & 1.13 & 1 & HLA-A25:01 & yes & $\&$ & \\
\hline 18 & P14625 & HSP90B1 & Endoplasmin & MMKLIINSL & 9 & 1.12 & 1 & HLA-B08:01 & yes & $\&$ & \\
\hline 19 & Q9UH77 & KLHL3 & Kelch-like protein 3 & EVYDPGTNTW & 10 & 1.10 & 1 & HLA-A25:01 & yes & $\& \#$ & \\
\hline 20 & Q5SRE5 & NUP188 & Nucleoporin NUP188 homolog & EVAPSFGTL & 9 & 1.06 & 1 & HLA-A25:01 & yes & $\&$ & \\
\hline 21 & Q53GT1 & KLHL22 & Kelch-like protein 22 & EEVLIHGVSY & 10 & 1.05 & $\mathrm{I}$ & HLA-B18:01 & yes & \&\# & \\
\hline 22 & Q96PU5 & NEDD4L & E3 ubiquitin-protein ligase NEDD4-like & ASDPYVKLSLY & 11 & 1.01 & 1 & HLA-A01:01 & yes & \&\# & \\
\hline 23 & P12270 & TPR & Nucleoprotein TPR & HLNTKELL & 8 & & $\mathrm{I}$ & HLA-B08:01 & & $\&$ & yes \\
\hline 24 & 000463 & TRAF5 & TNF receptor-associated factor 5 & EVIKSQEVF & 9 & & 1 & HLA-A25:01 & & & yes \\
\hline 25 & 015439 & $A B C C 4$ & Multidrug resistance-associated protein 4 & EVITGIRII & 9 & & 1 & HLA-A25:01 & & & yes \\
\hline 26 & Q9NX02 & NLRP2 & NACHT, LRR and PYD domains-containing protein 2 & LLDEGAKLLY & 10 & & 1 & HLA-A01:01 & & & yes \\
\hline 27 & P01850 & TRBC1 & T-cell receptor beta-1 chain C region & YEILLGKATLY & 11 & & 1 & HLA-B18:01 & & & yes \\
\hline
\end{tabular}

HLA-I alleles with relatively higher binding affinity for immunopeptides were listed. 
Fig. $\mathbf{6} 6$

\begin{tabular}{|c|c|c|c|c|c|c|c|c|c|c|c|c|c|}
\hline \multirow[b]{2}{*}{ No. } & \multirow[b]{2}{*}{ Uniprot ID } & \multirow[b]{2}{*}{$\begin{array}{l}\text { Protein } \\
\text { symbol }\end{array}$} & \multirow[b]{2}{*}{ Protein name } & \multirow[b]{2}{*}{ Sequence } & \multirow[b]{2}{*}{ Length } & \multirow[b]{2}{*}{$\begin{array}{l}\text { Log2 Fold } \\
\text { change }\end{array}$} & \multirow[b]{2}{*}{$\begin{array}{l}\text { HLA } \\
\text { class }\end{array}$} & \multirow[b]{2}{*}{ HLA alleles } & \multicolumn{3}{|c|}{ Criteria } & \multirow{2}{*}{\begin{tabular}{|c|} 
MixMHC2pred \\
$\begin{array}{c}\text { \%Rank_best } \\
\text { score }\end{array}$ \\
\end{tabular}} & \multirow[b]{2}{*}{ PRM } \\
\hline & & & & & & & & & $\begin{array}{l}\text { Significant } \\
\text { diffierence }\end{array}$ & $\begin{array}{c}\text { Biological } \\
\text { significance* }\end{array}$ & $\begin{array}{l}\text { ID in T1D } \\
\text { only }\end{array}$ & & \\
\hline 1 & P09668 & CTSH & Pro-cathepsin $\mathrm{H}$ & LPSQAFEYILYNKGIM & 16 & 3.23 & II & HLA-DPA1*01:03-DPB1*04:01 & yes & $\& \#$ & & 0.039 & yes \\
\hline 2 & P61769 & B2M & Beta-2-microglobulin & YLLYYTEFTPTEKDEY & 16 & 2.52 & II & HLA-DPA1*01:03-DPB1*04:01 & yes & $\&$ & & 0.482 & yes \\
\hline 3 & 075787 & ATP6AP2 & Renin receptor & DASKILVDALQKFADD & 16 & 2.42 & II & HLA-DRB1*03:01 & yes & $\&$ & & 0.129 & yes \\
\hline 4 & P26951 & IIL3RA & Interleukin-3 receptor subunit alpha & GPGAPADVQYDLYLNVANR & 19 & 2.31 & II & HLA-DPA1*01:03-DPB1*04:01 & yes & $\&$ & & 0.286 & yes \\
\hline 5 & P01374 & LTA & Lymphotoxin-alpha & HSMYHGAAFQLTQGDQ & 16 & 2.24 & II & HLA-DQA1*05:01-DQB1*03:02 & yes & $\&$ & & NA & \\
\hline 6 & 014672 & ADAM10 & $\begin{array}{l}\text { Disintegrin and metalloproteinase domain-containing } \\
\text { protein } 10\end{array}$ & FPNIGVEKFLELNSE & 15 & 2.11 & ॥ & HLA-DPA1*01:03-DPB $1 * 04: 01$ & yes & $\&$ & & 0.00988 & yes \\
\hline 7 & P07437 & TUBB & Tubulin beta chain & GDSDLQLDRISVYYNEA & 17 & 1.93 & II & HLA-DRB1*03:01 & yes & $\&$ & & 0.737 & yes \\
\hline 8 & P11142 & HSPA8 & Heat shock cognate $71 \mathrm{kDa}$ protein & VLRIINEPTAAAIAYG & 16 & 1.78 & II & HLA-DQA1*05:01-DQB1*03:02 & yes & $\&$ & & NA & yes \\
\hline 9 & P09668 & CTSH & Pro-cathepsin H & LPSQAFEYILYNKGI & 15 & 1.77 & II & HLA-DPA1*01:03-DPB1*04:01 & yes & \&\# & & 0.47 & yes \\
\hline 10 & P13164 & IFITM1 & Interferon-induced transmembrane protein 1 & VPDHVVVWSLFNTL & 13 & 1.51 & II & HLA-DPA1*01:03-DPB1*02:01 & yes & $\&$ & & 0.0548 & yes \\
\hline 11 & P09668 & CTSH & Pro-cathepsin $\mathrm{H}$ & LPSQAFEYILYNKG & 14 & 1.38 & II & HLA-DPA1*01:03-DPB1*04:01 & yes & \&\# & & 0.288 & yes \\
\hline 12 & Q12913 & PTPRJ & Receptor-type tyrosine-protein phosphatase eta & DVYGIVYDLRMHRP & 14 & 1.37 & 11 & HLA-DRB1*03:01 & yes & $\&$ & & 0.00412 & \\
\hline 13 & 015143 & ARPC1B & Actin-related protein $2 / 3$ complex subunit $1 \mathrm{~B}$ & ALTFITDNSLVAAGHD & 16 & 1.28 & II & HLA-DRB1*04:01 & yes & $\&$ & & 0.0195 & yes \\
\hline 14 & Q13114 & TRAF3 & TNF receptor-associated factor 3 & GDAFKPDPNSSSFKKPT & 17 & 1.21 & II & HLA-DRB1*04:01 & yes & $\&$ & & 0.316 & yes \\
\hline 15 & P11142 & HSPA8 & Heat shock cognate $71 \mathrm{kDa}$ protein & ERAMTKDNNLLGKFEL & 16 & 1.15 & II & HLA-DRB1*03:01 & yes & $\&$ & & 0.382 & yes \\
\hline 16 & Q9H3Z4 & DNAIC5 & DnaJ homolog subfamily $\mathrm{C}$ member 5 & TTQLTADSHPSYHTDG & 16 & 1.11 & II & HLA-DRB1*03:01 & yes & $\&$ & & 0.757 & yes \\
\hline 17 & P25774 & CTSS & Cathepsin S & NGGFMTTAFQYIIDNK & 16 & 1.10 & II & HLA-DPA1*01:03-DPB1*04:01 & yes & \&\# & & 0.0119 & yes \\
\hline 18 & P11142 & HSPA8 & Heat shock cognate $71 \mathrm{kDa}$ protein & VLRIINEPTAAAIAY & 15 & 1.04 & II & HLA-DQA1*05:01-DQB1*03:02 & yes & $\&$ & & NA & yes \\
\hline 19 & P14618 & PKM & Pyruvate kinase PKM & DENILWLDYKNICKVVE & 17 & & II & HLA-DRB1*03:01 & & $\&$ & yes & 0.497 & \\
\hline 20 & P21580 & TNFAIP3 & Tumor necrosis factor alpha-induced protein 3 & EINLVDDYFELVQHE & 15 & & II & HLA-DQA1*03:01-DQB1*02:01 & & $\&$ & yes & NA & yes \\
\hline 21 & P52907 & CAPZA1 & F-actin-capping protein subunit alpha-1 & FNEVFNDVRLLLNNDN & 16 & & II & HLA-DRB1*03:01 & & \&\# & yes & 0.00543 & \\
\hline 22 & P10147 & CCL3 & C-C motif chemokine 3 & IPQNFIADYFETSSQ & 15 & & II & HLA-DPA1*01:03-DPB1*04:01 & & $\&$ & yes & 0.0053 & yes \\
\hline 23 & 000754 & MAN2B1 & Lysosomal alpha-mannosidase & IRATFDPDTGLLMEIM & 16 & & II & HLA-DRB1*03:01 & & $\&$ & yes & 0.117 & \\
\hline 24 & P26951 & IL3RA & Interleukin-3 receptor subunit alpha & GPGAPADVQYDLYLNVA & 17 & & II & HLA-DPA1*01:03-DPB1*04:01 & & $\&$ & yes & 0.434 & \\
\hline 25 & P09668 & CTSH & Pro-cathepsin $\mathrm{H}$ & LPSQAFEYILYNKGIMGED & 19 & & II & HLA-DPA1*01:03-DPB1*04:01 & & \&\# & yes & 0.754 & yes \\
\hline
\end{tabular}


Fig. 57

Pages: $10-37$

10 

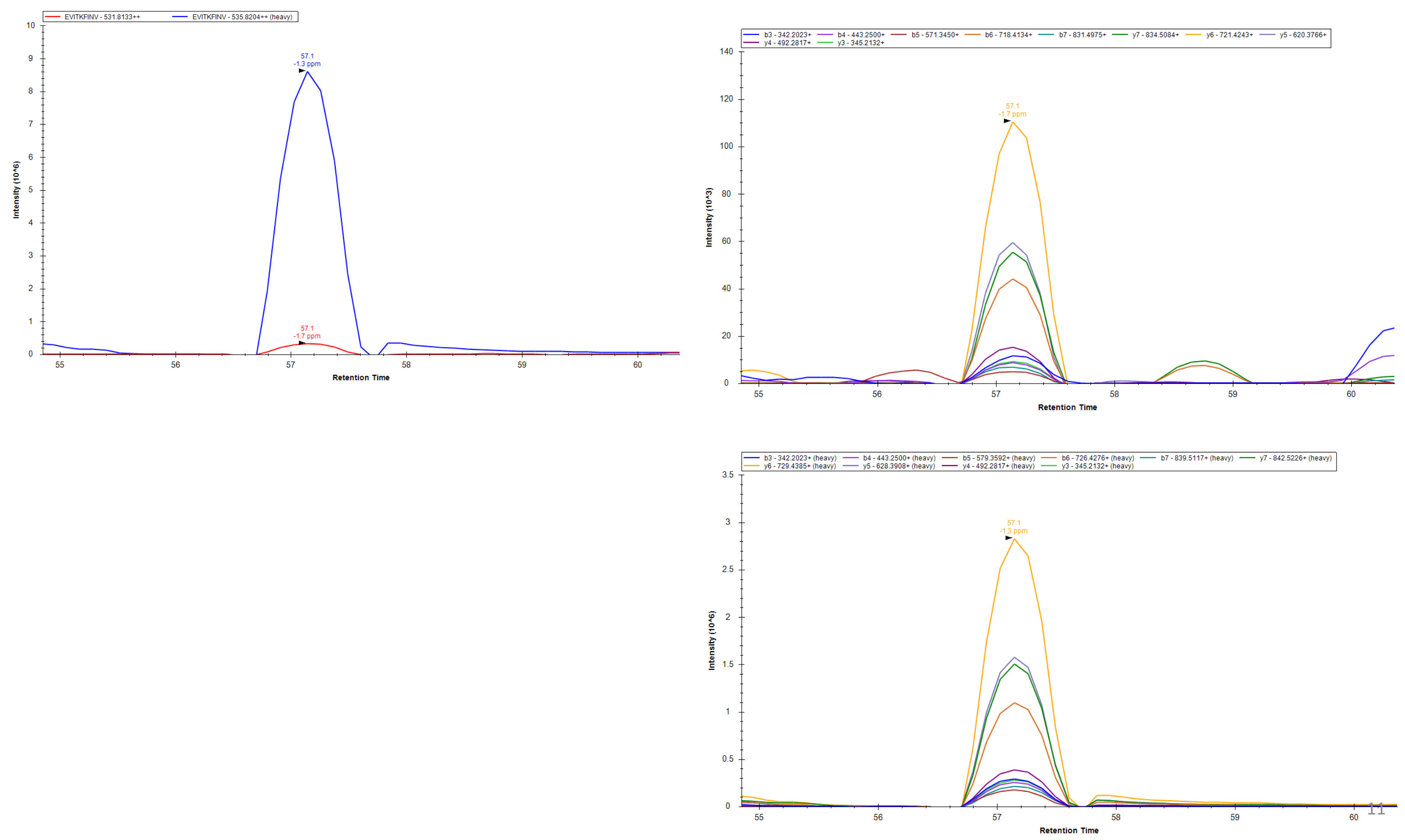

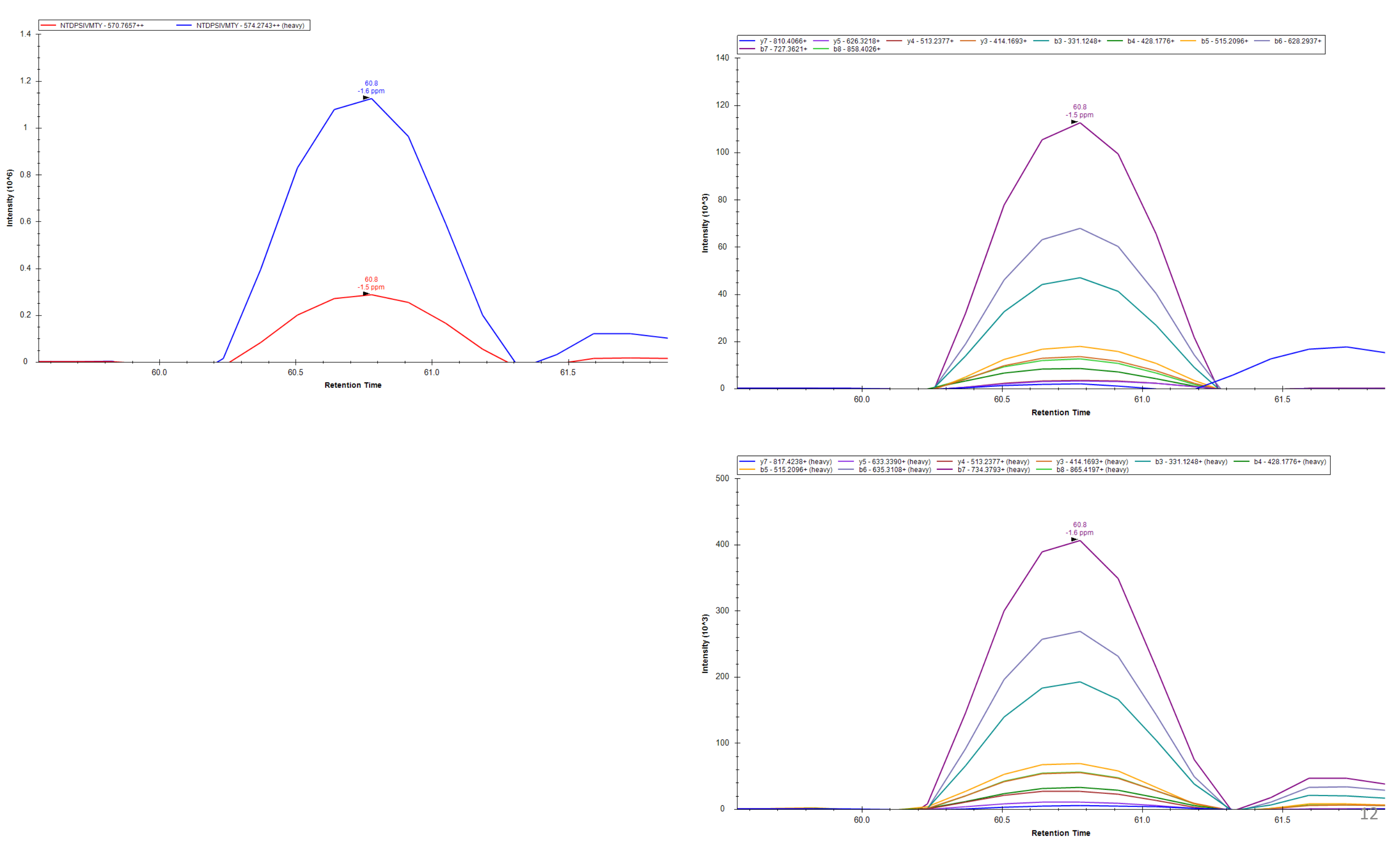

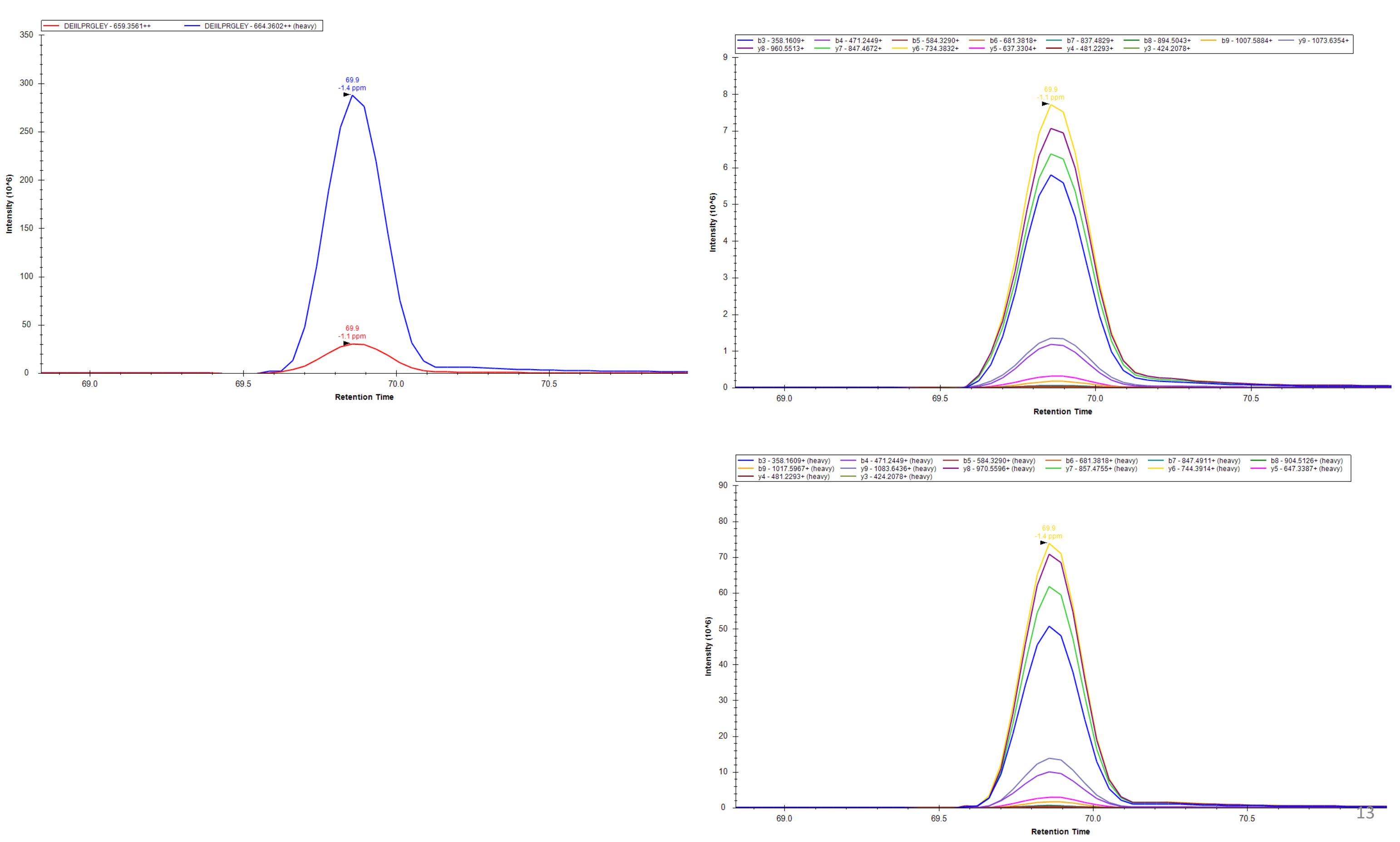

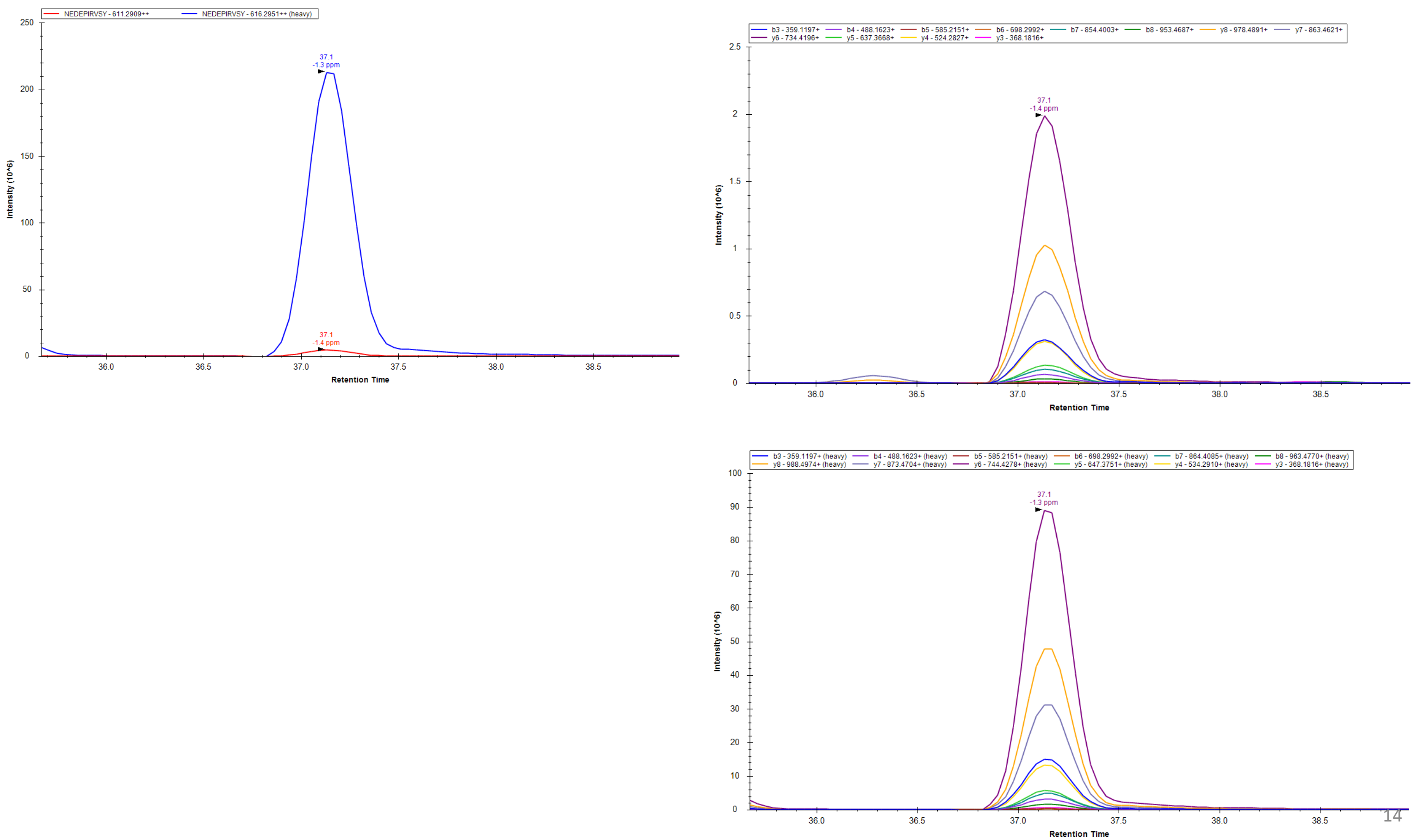

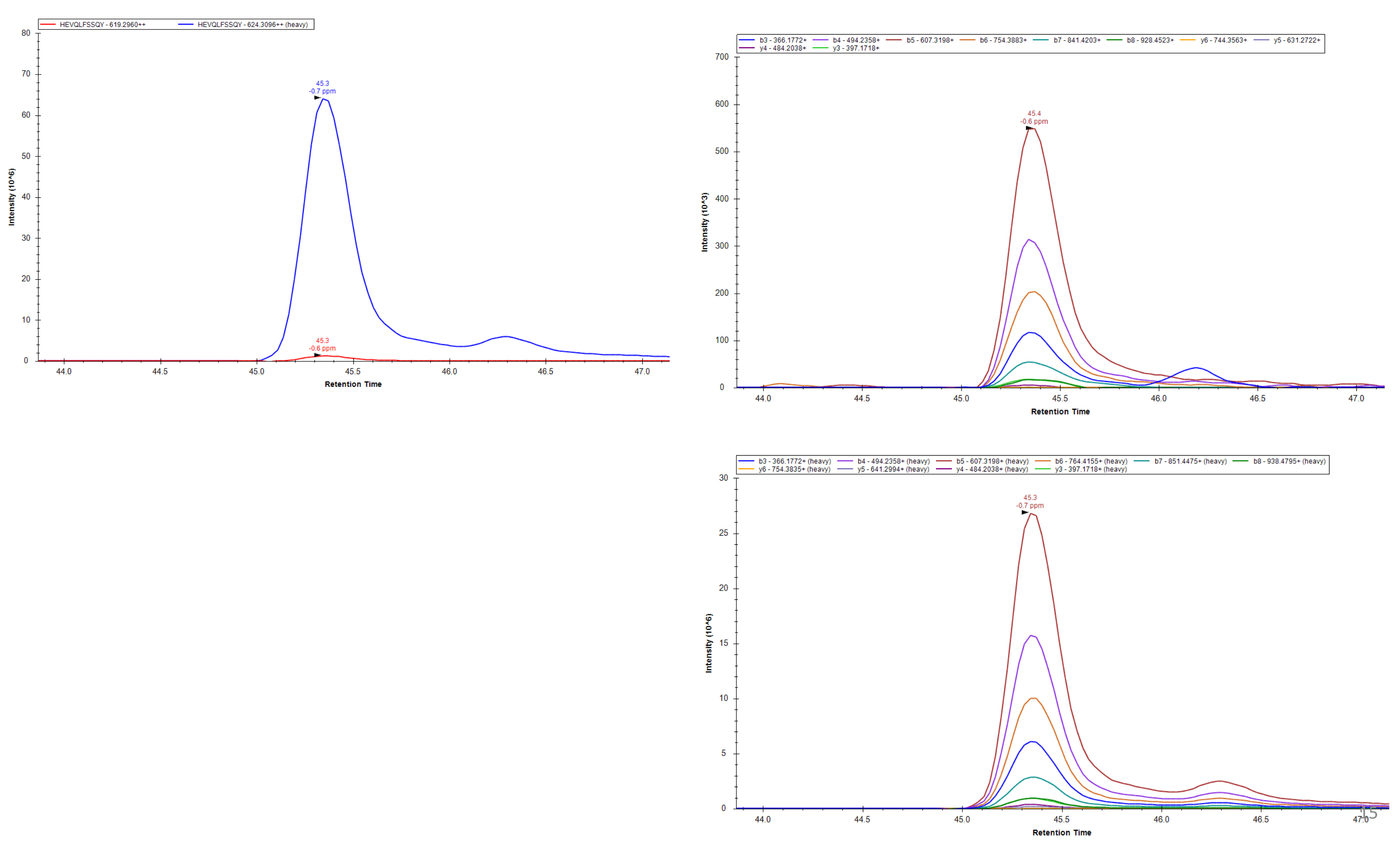



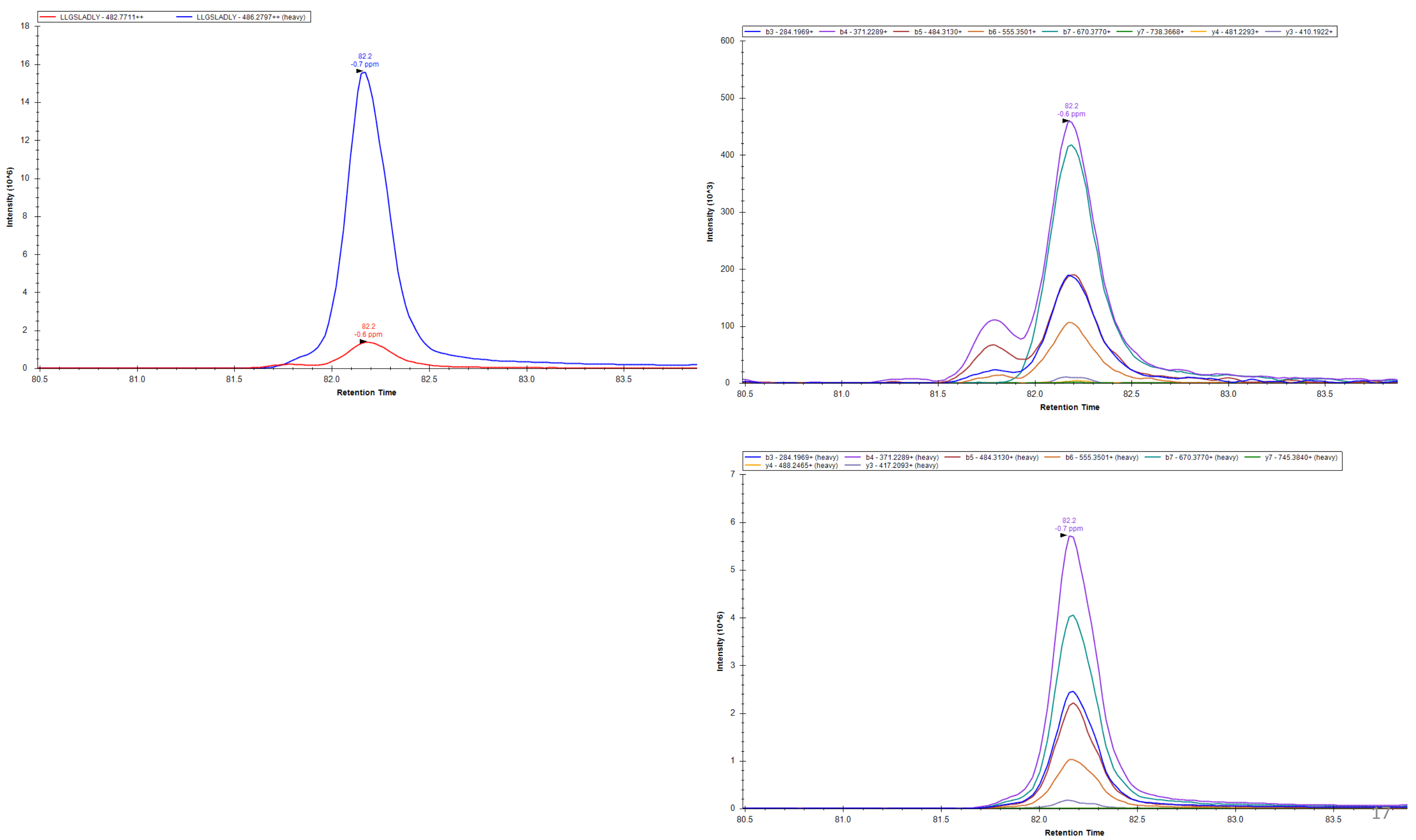

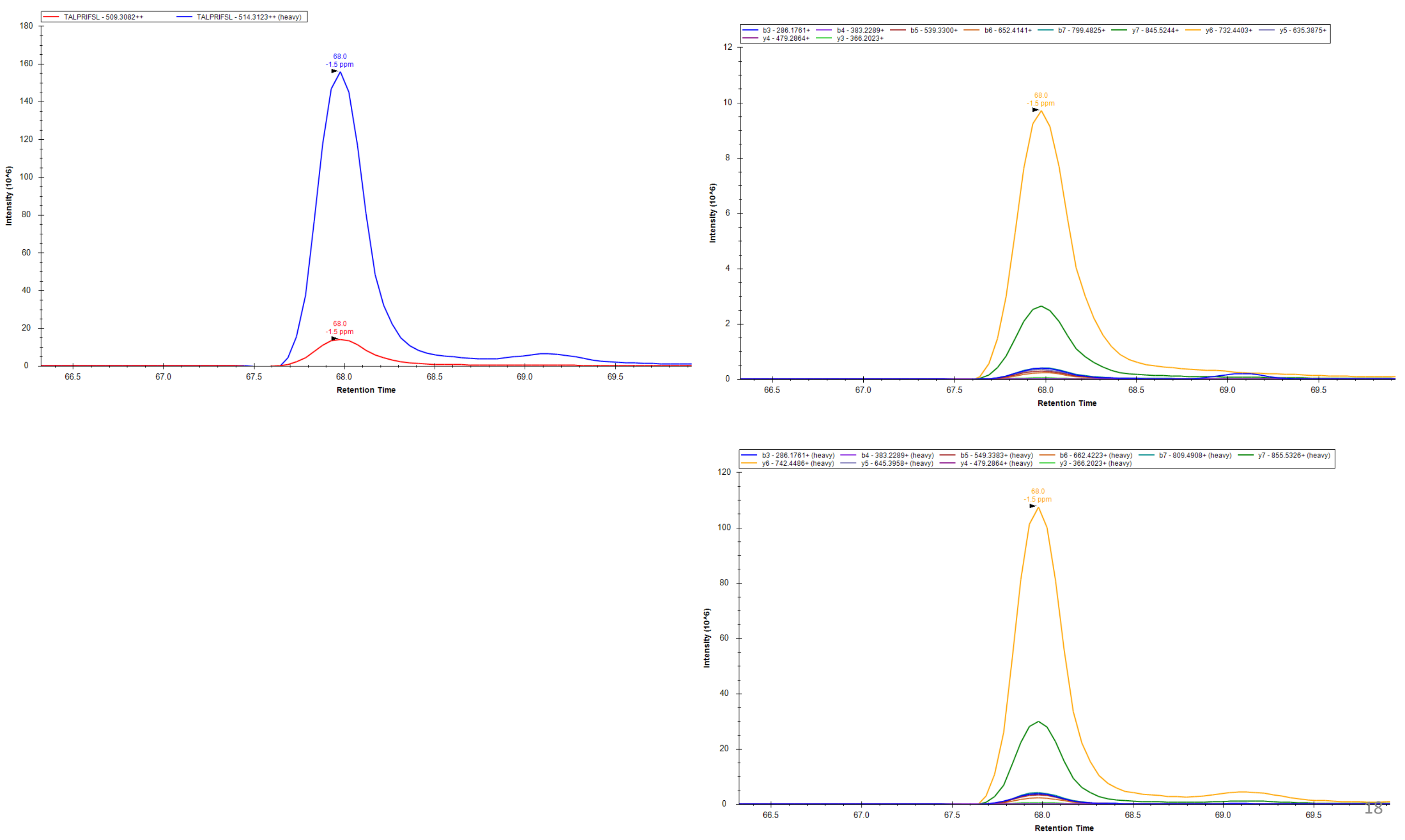

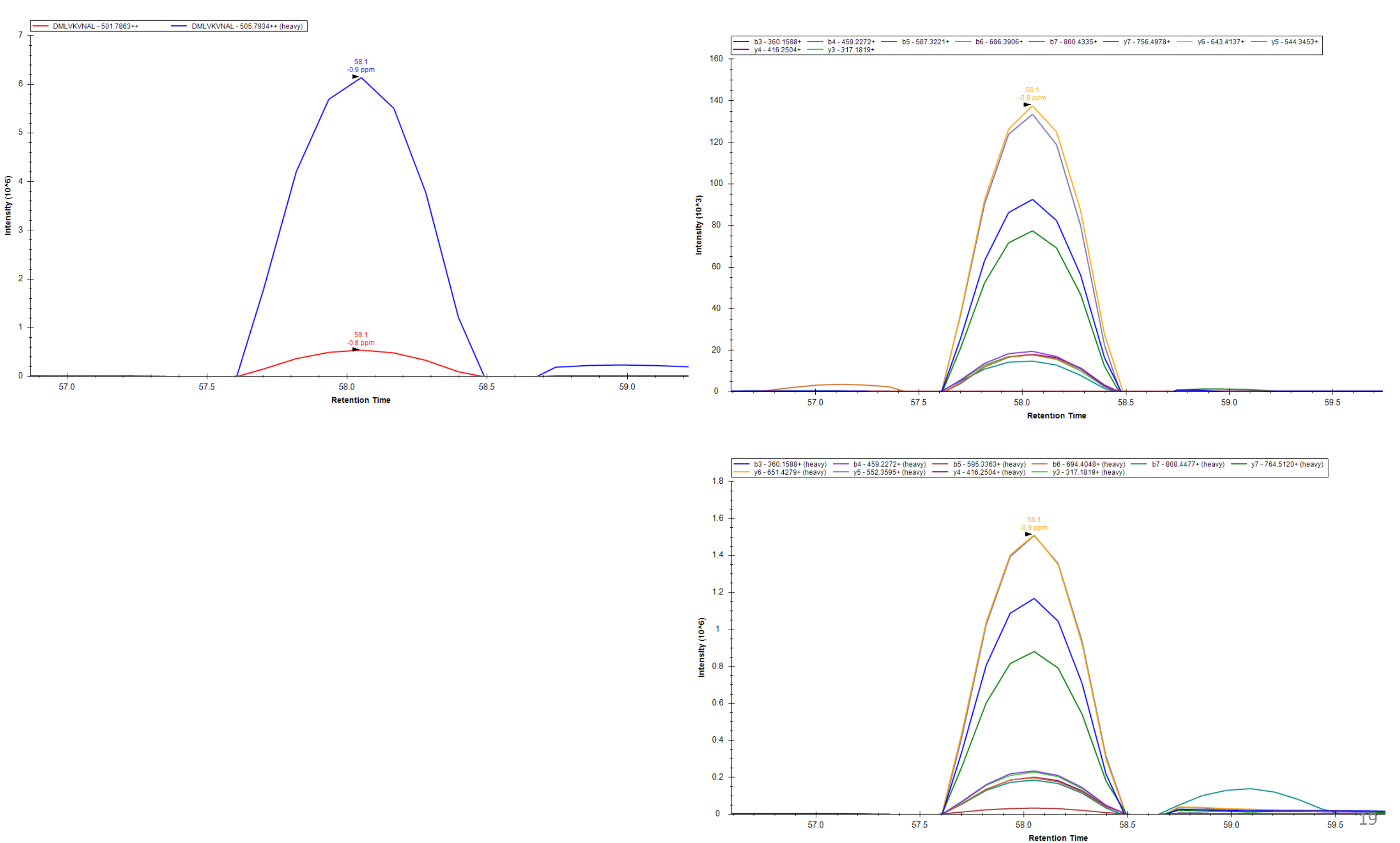

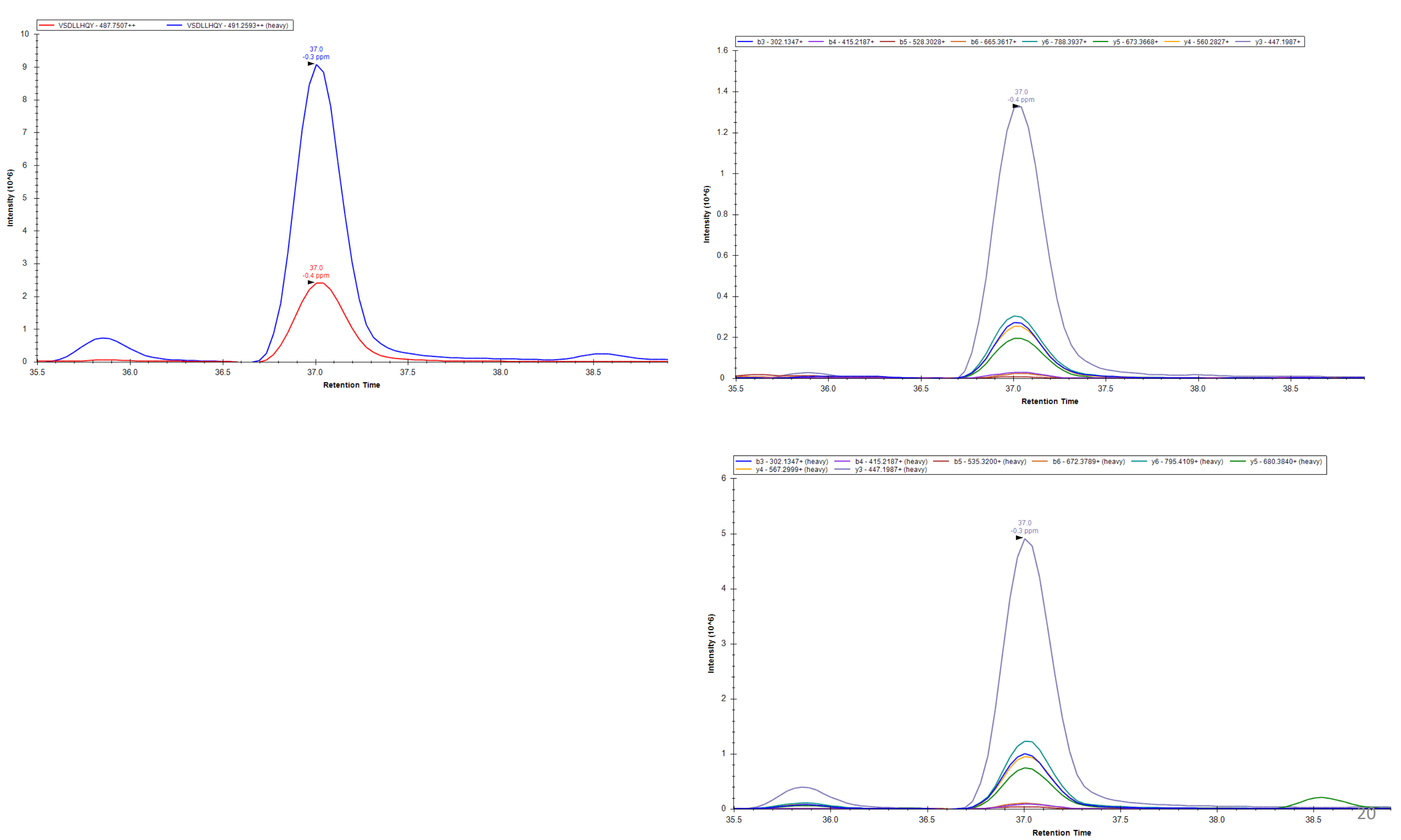







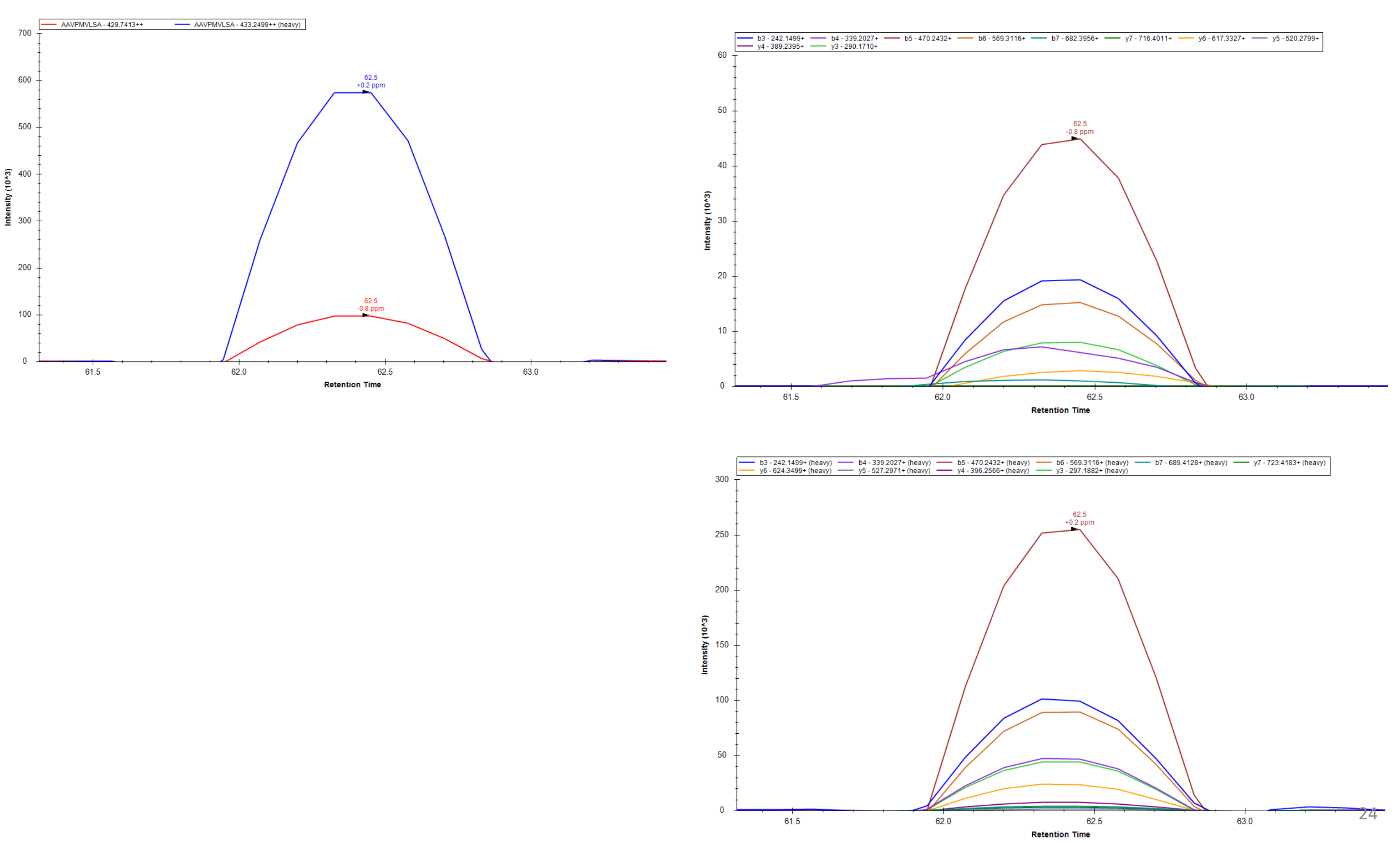

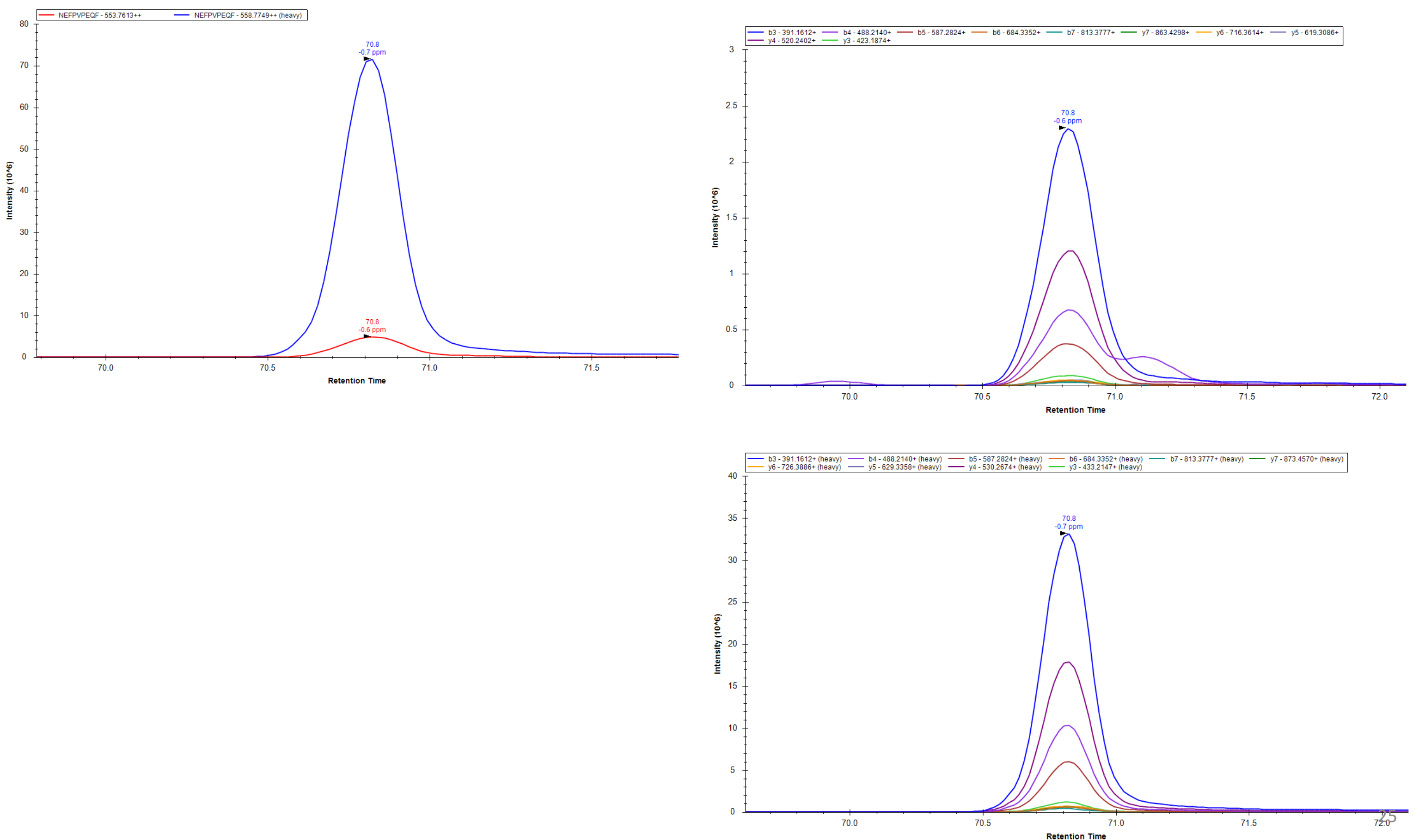

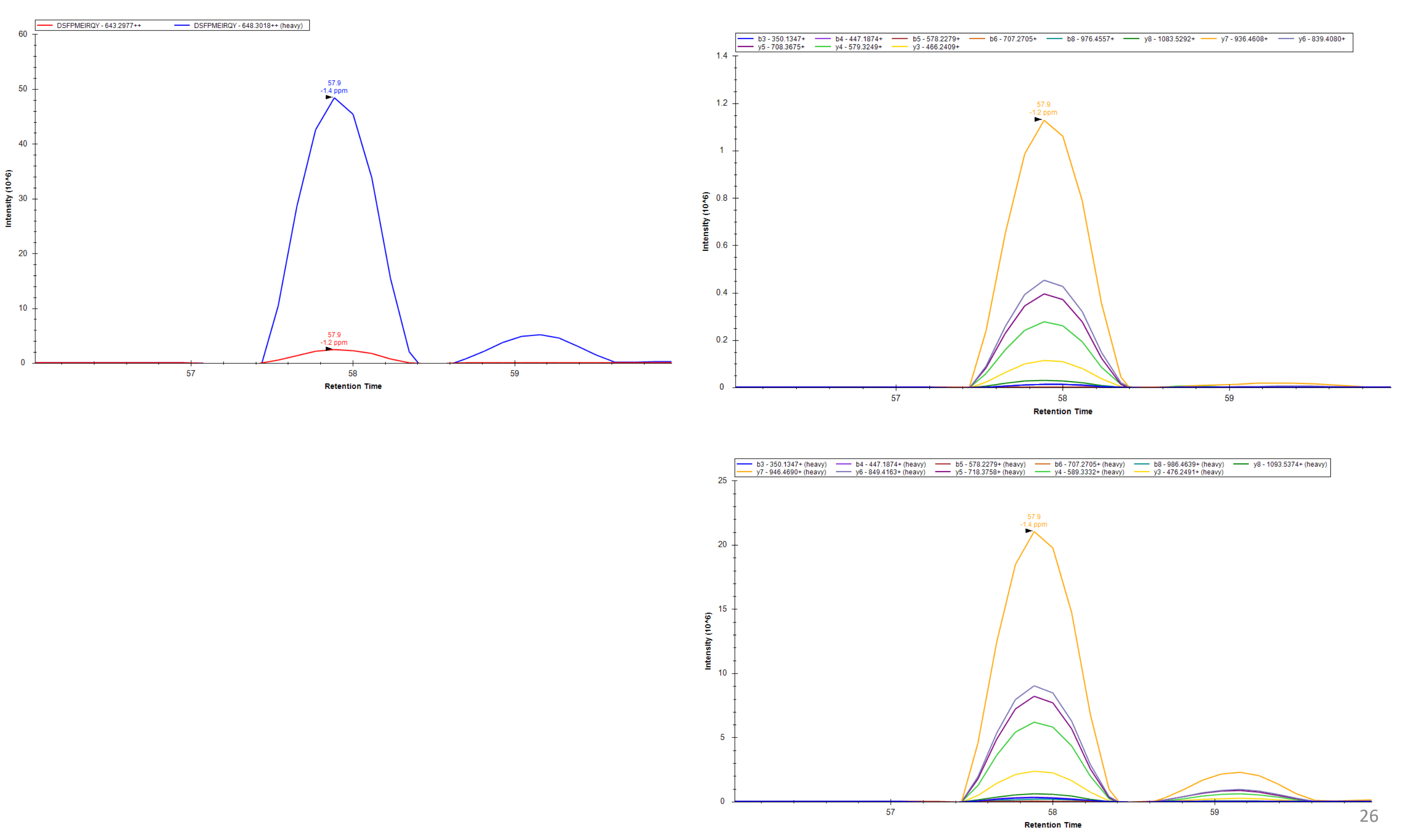

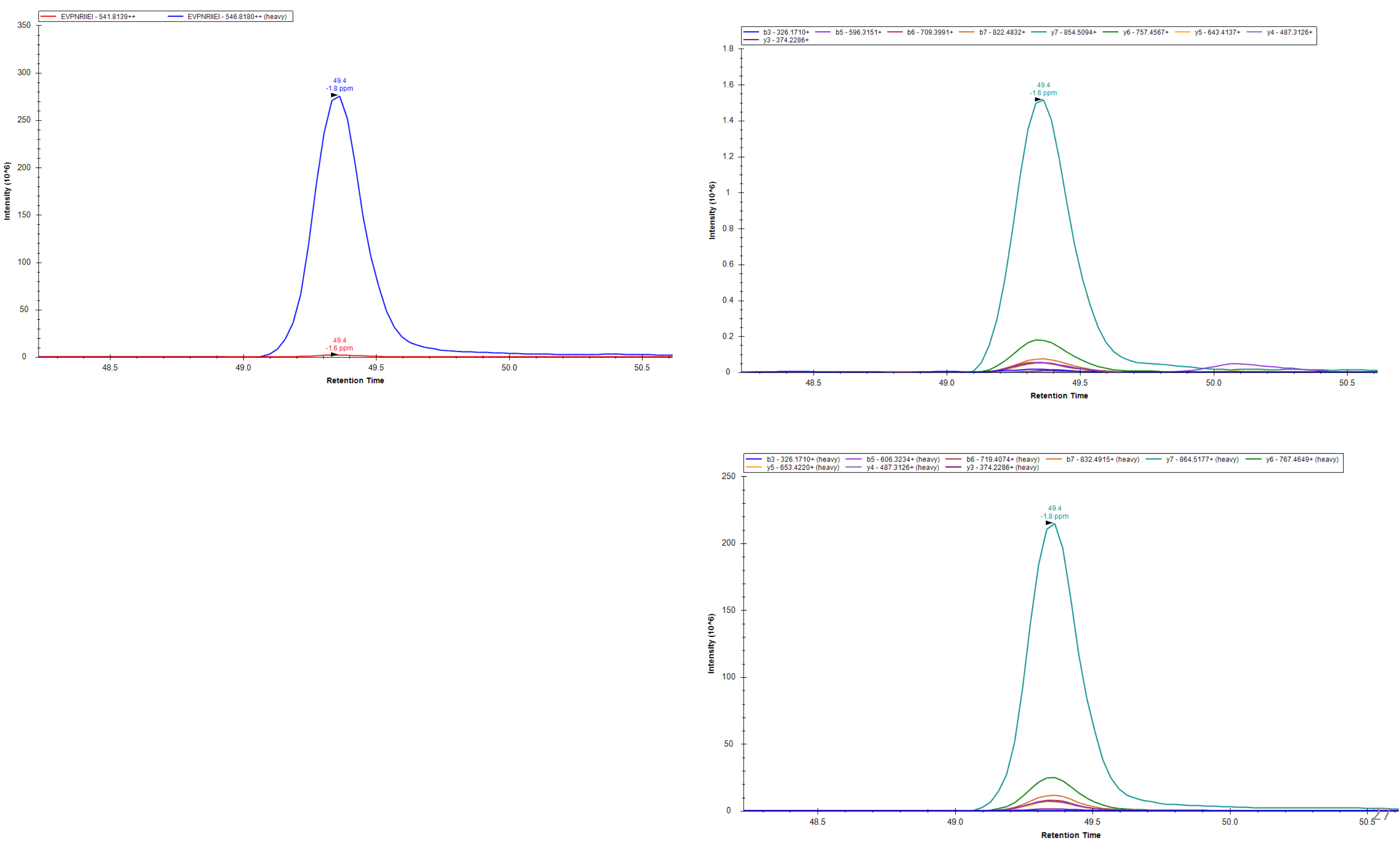

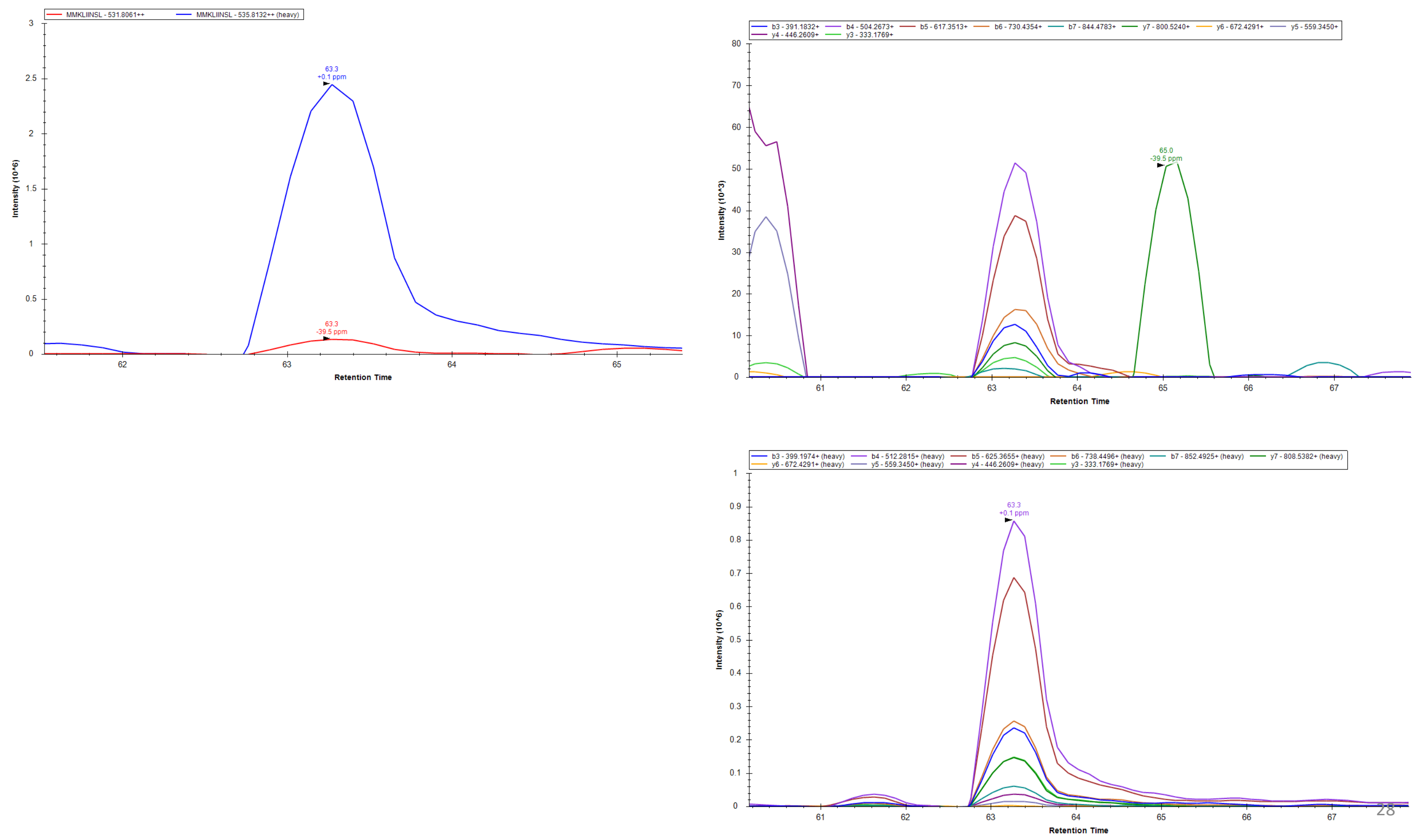

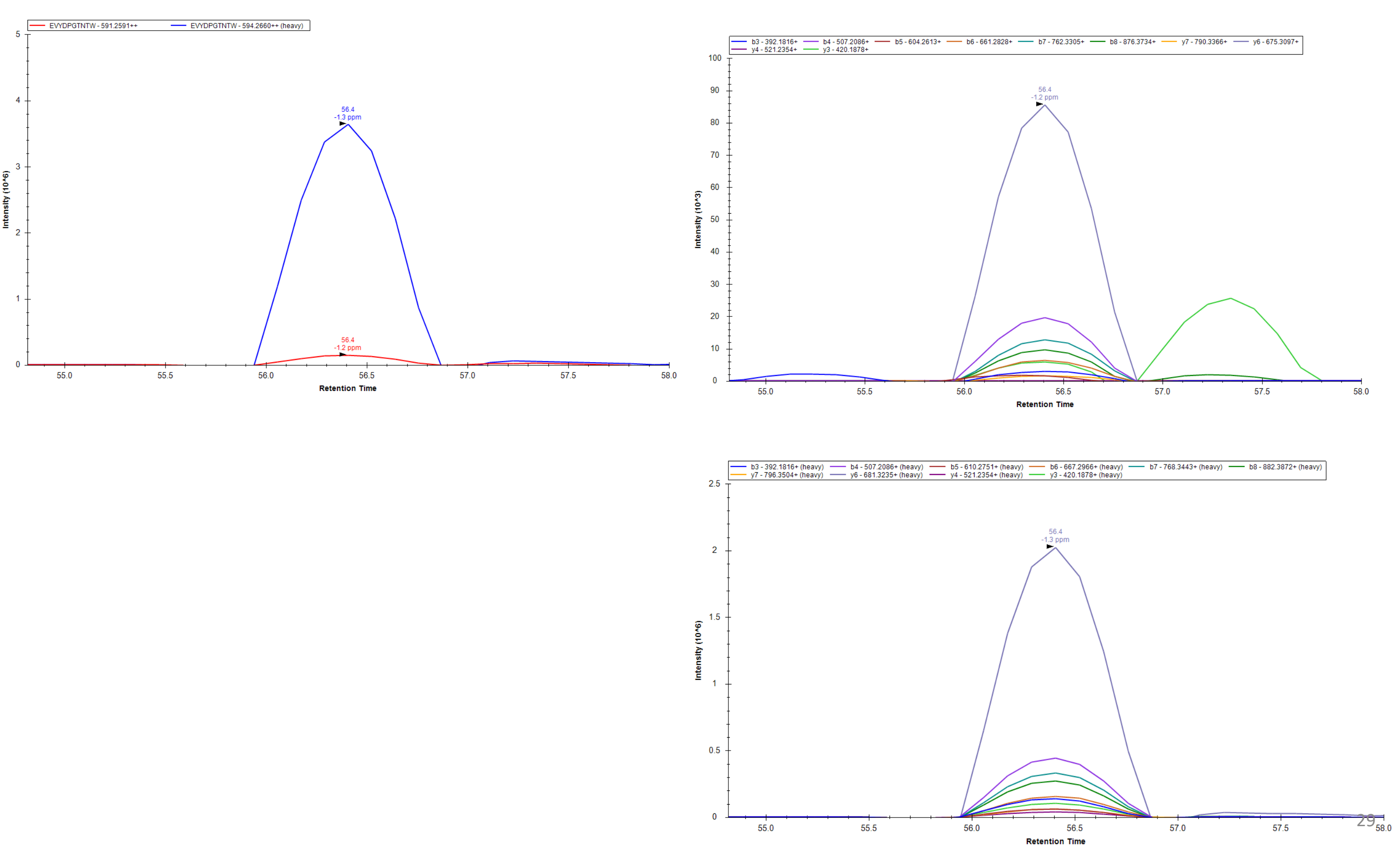

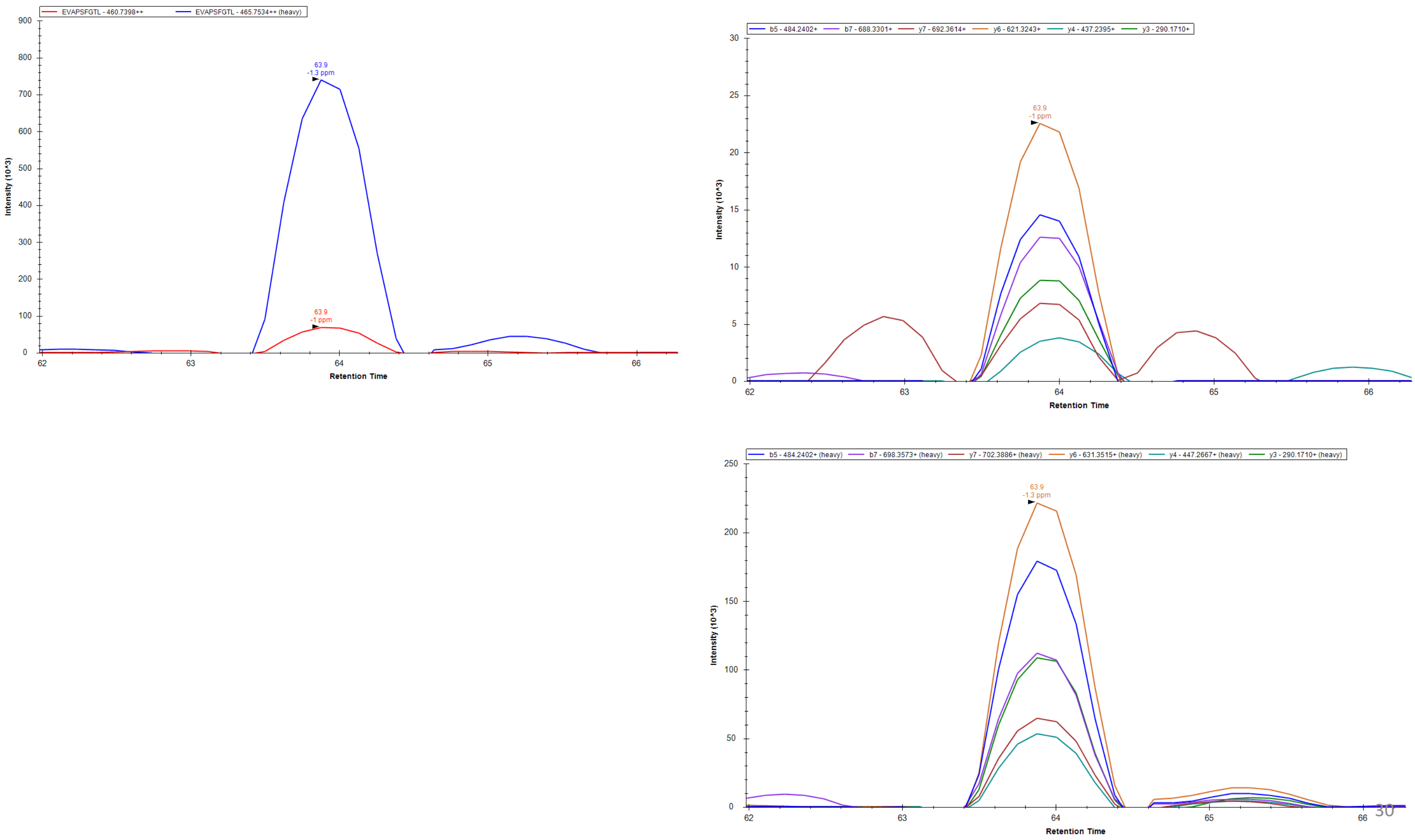






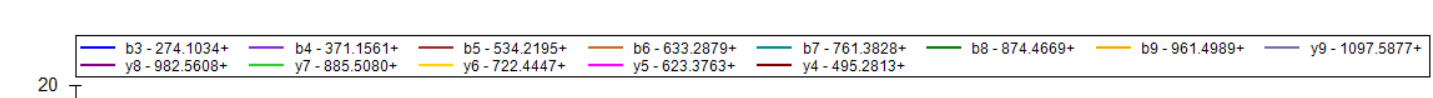
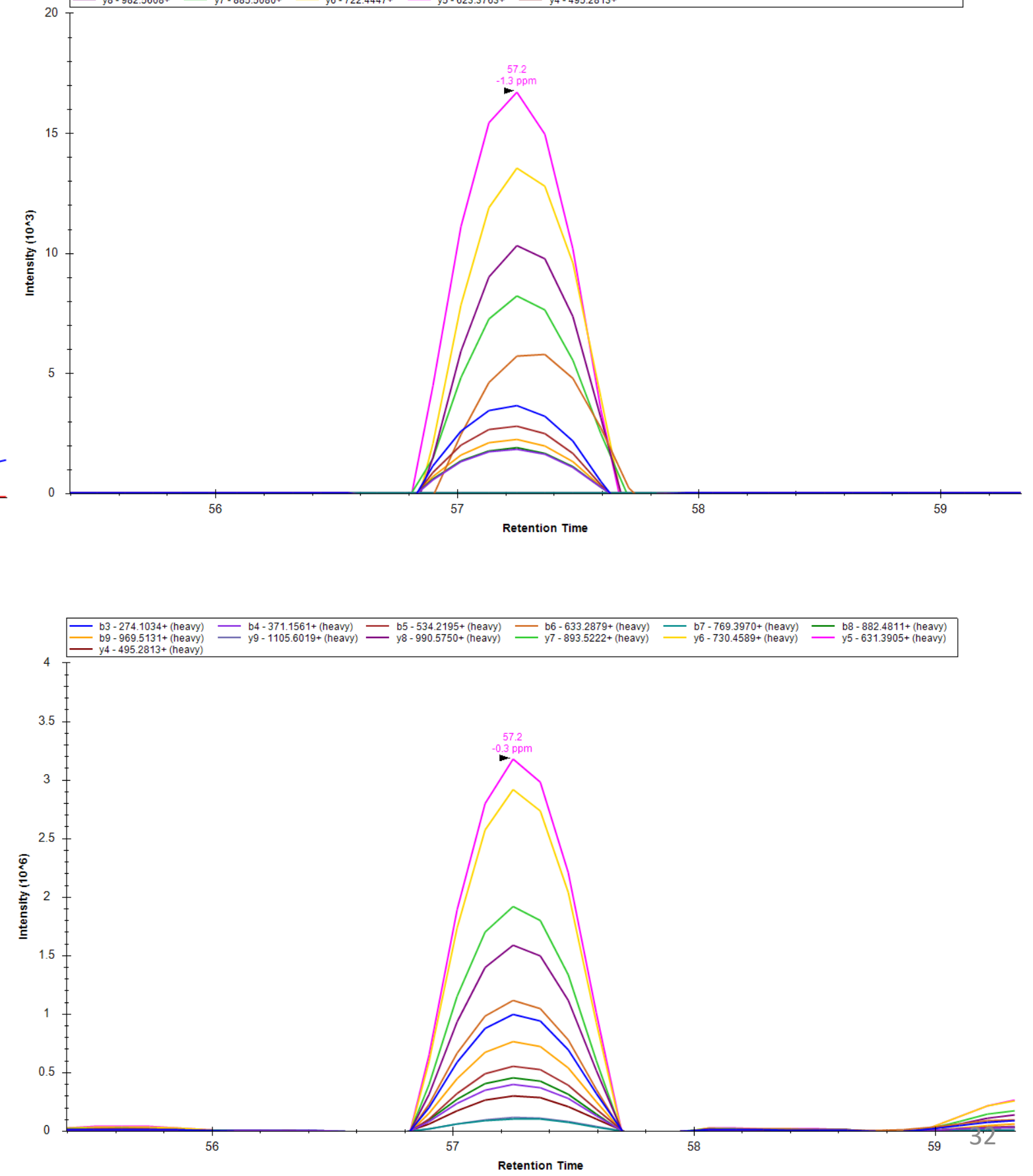

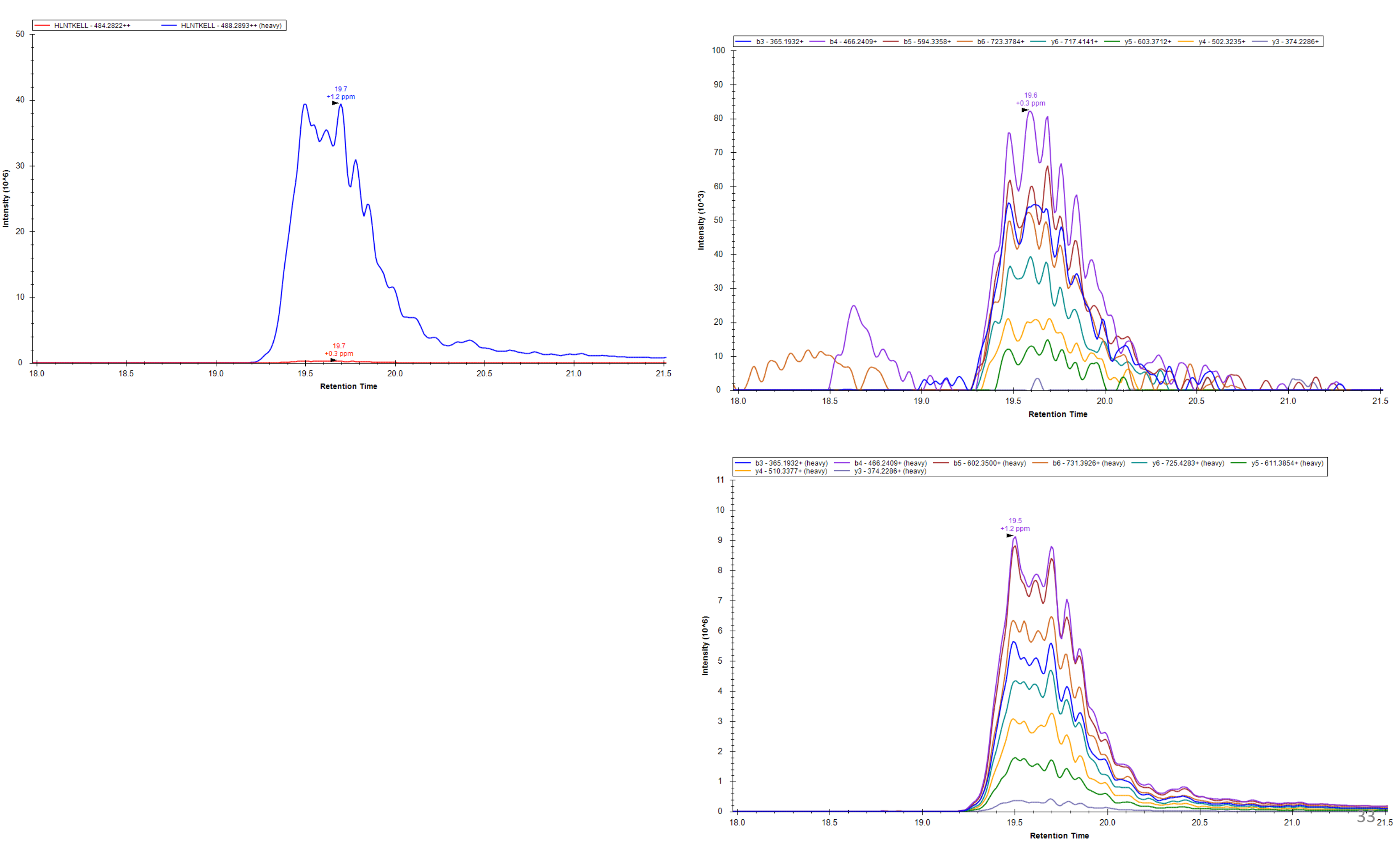

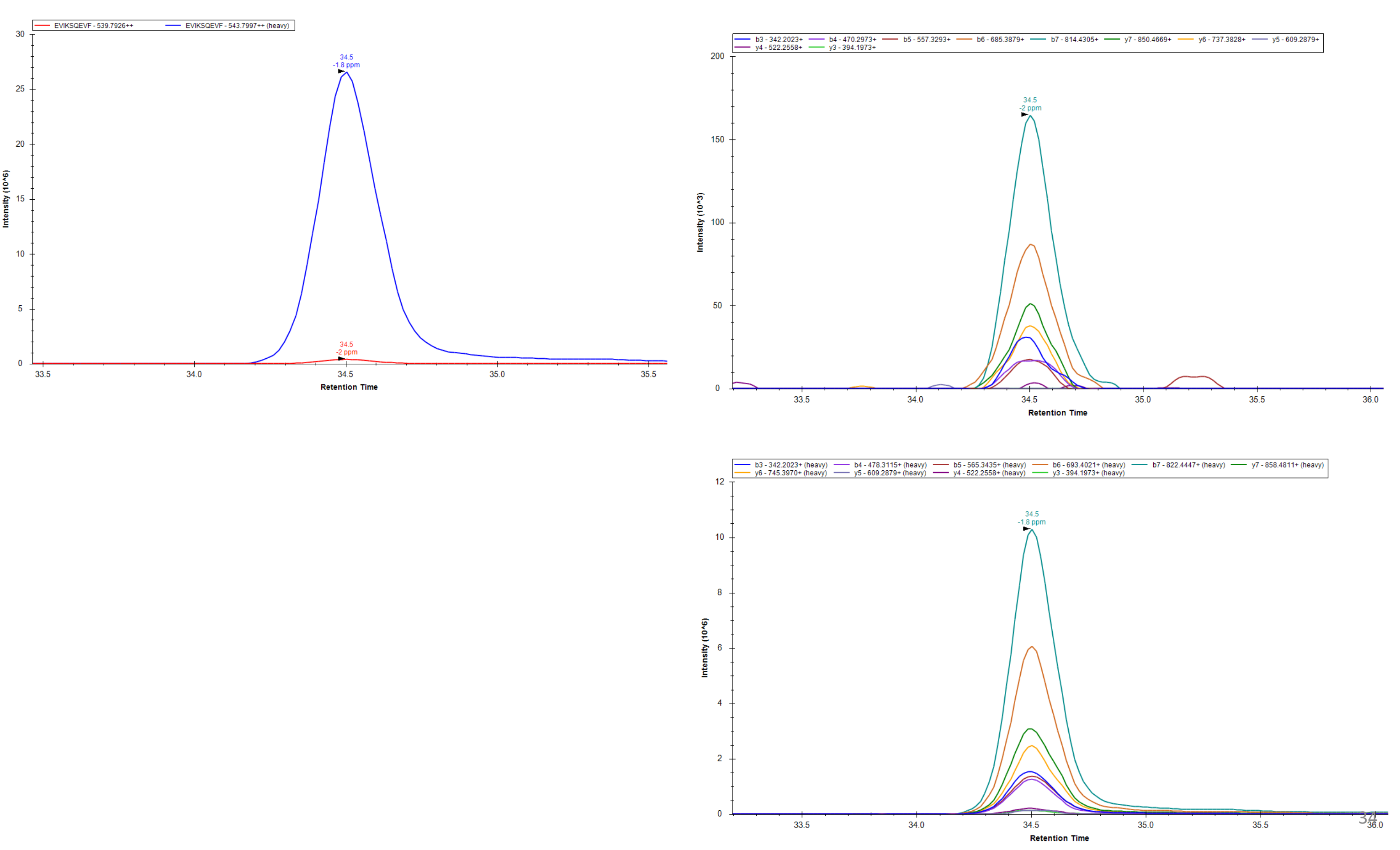

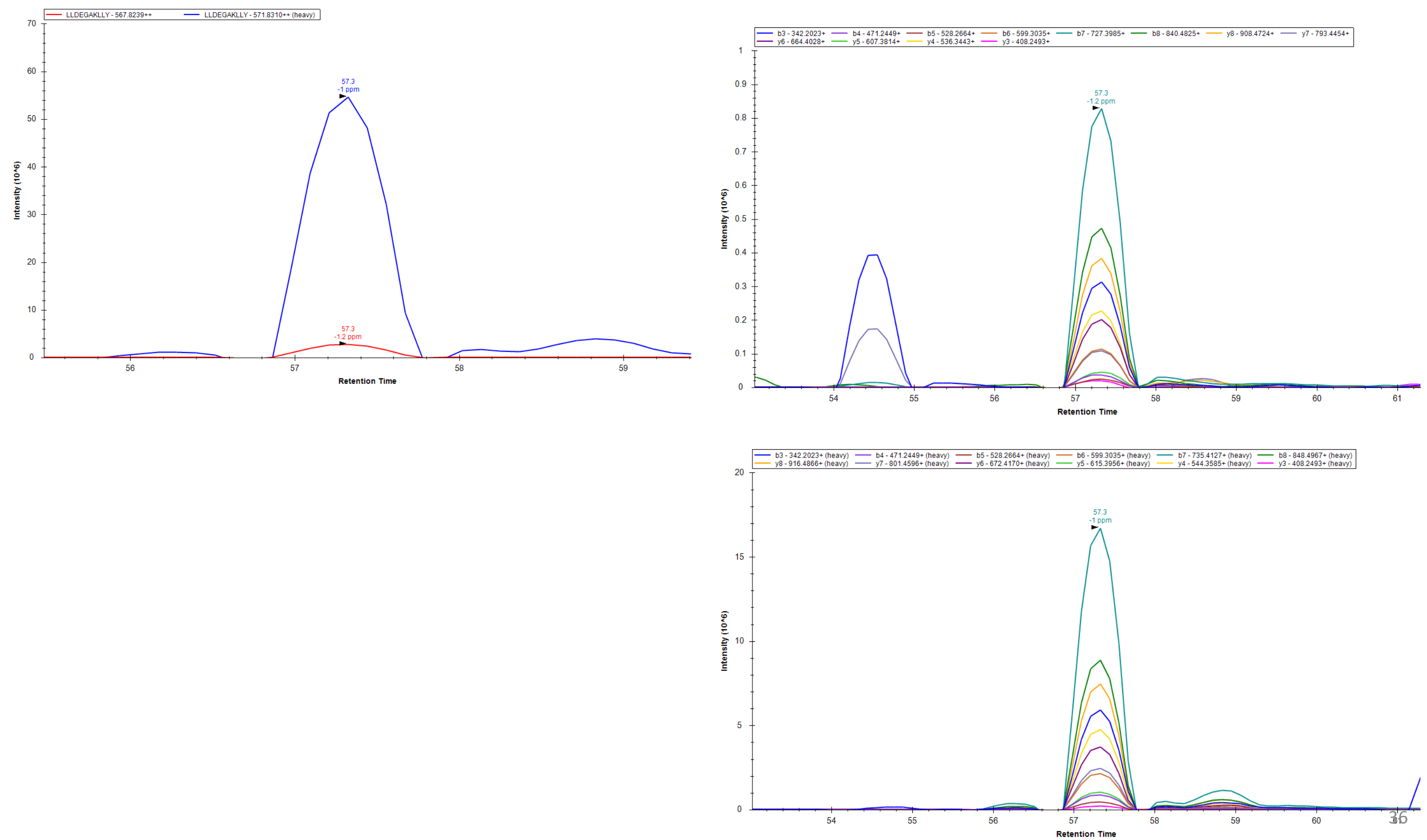
Fig. S8

Pages: $38-67$ 



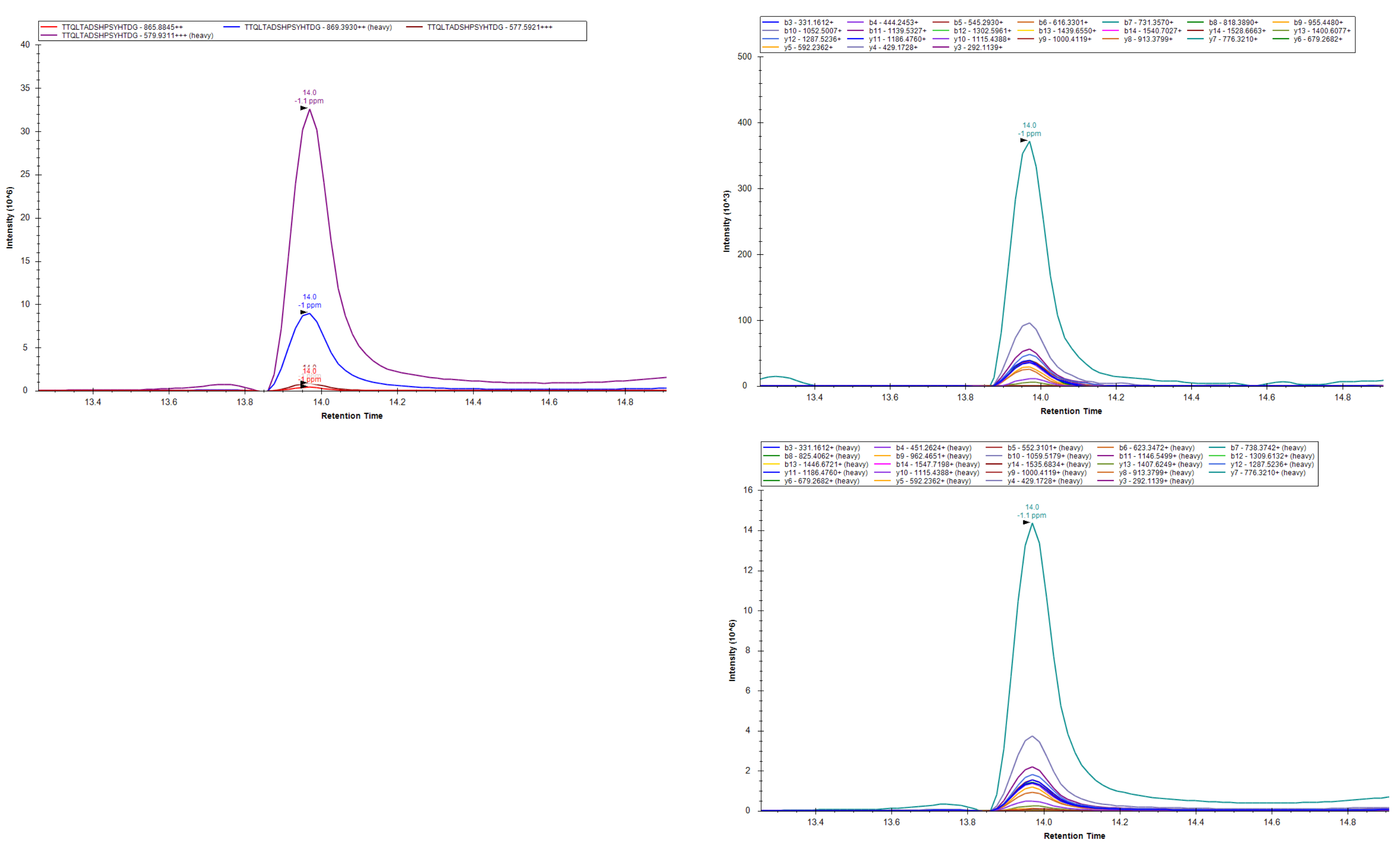



46 

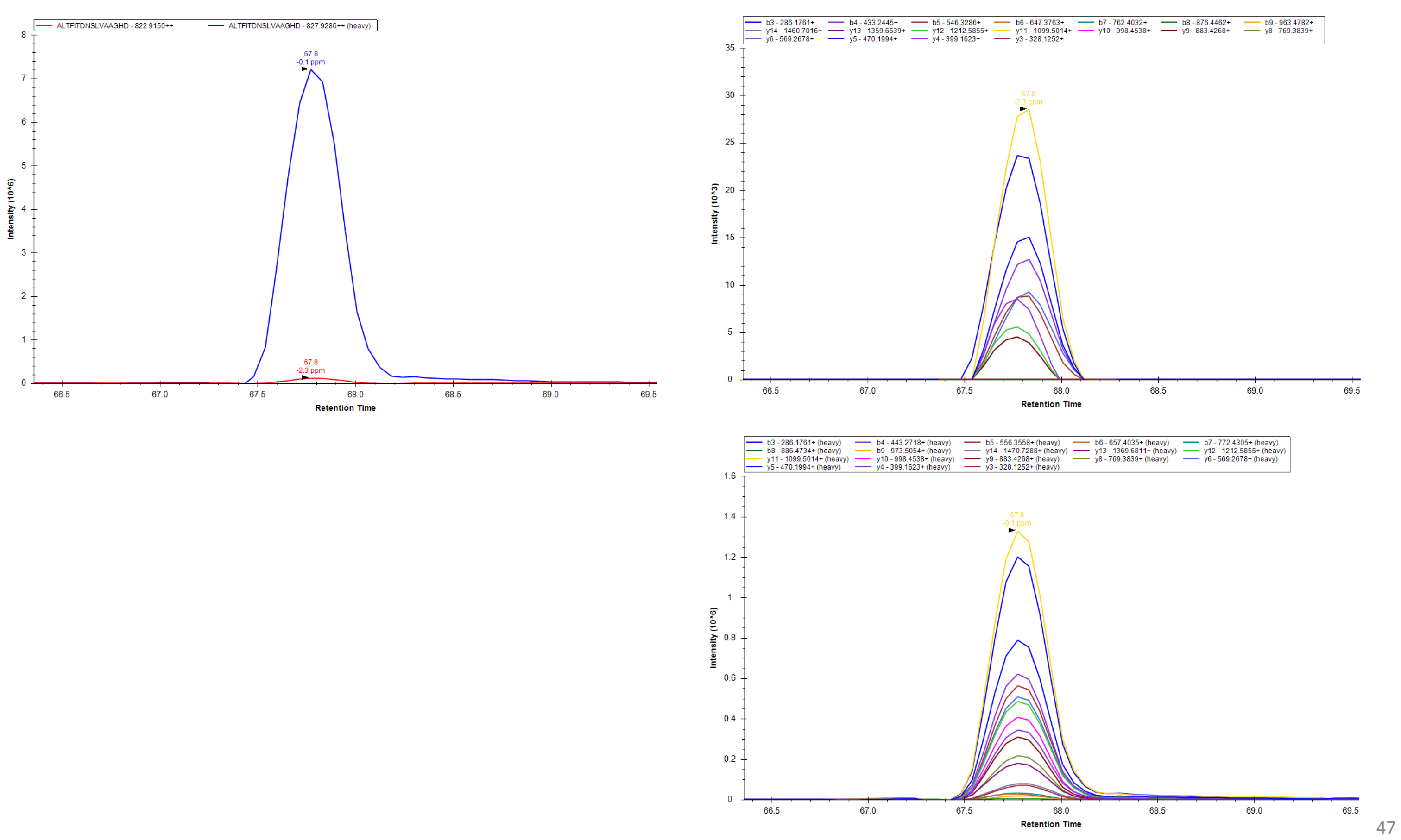


LPSQAFEYILYNKGIM

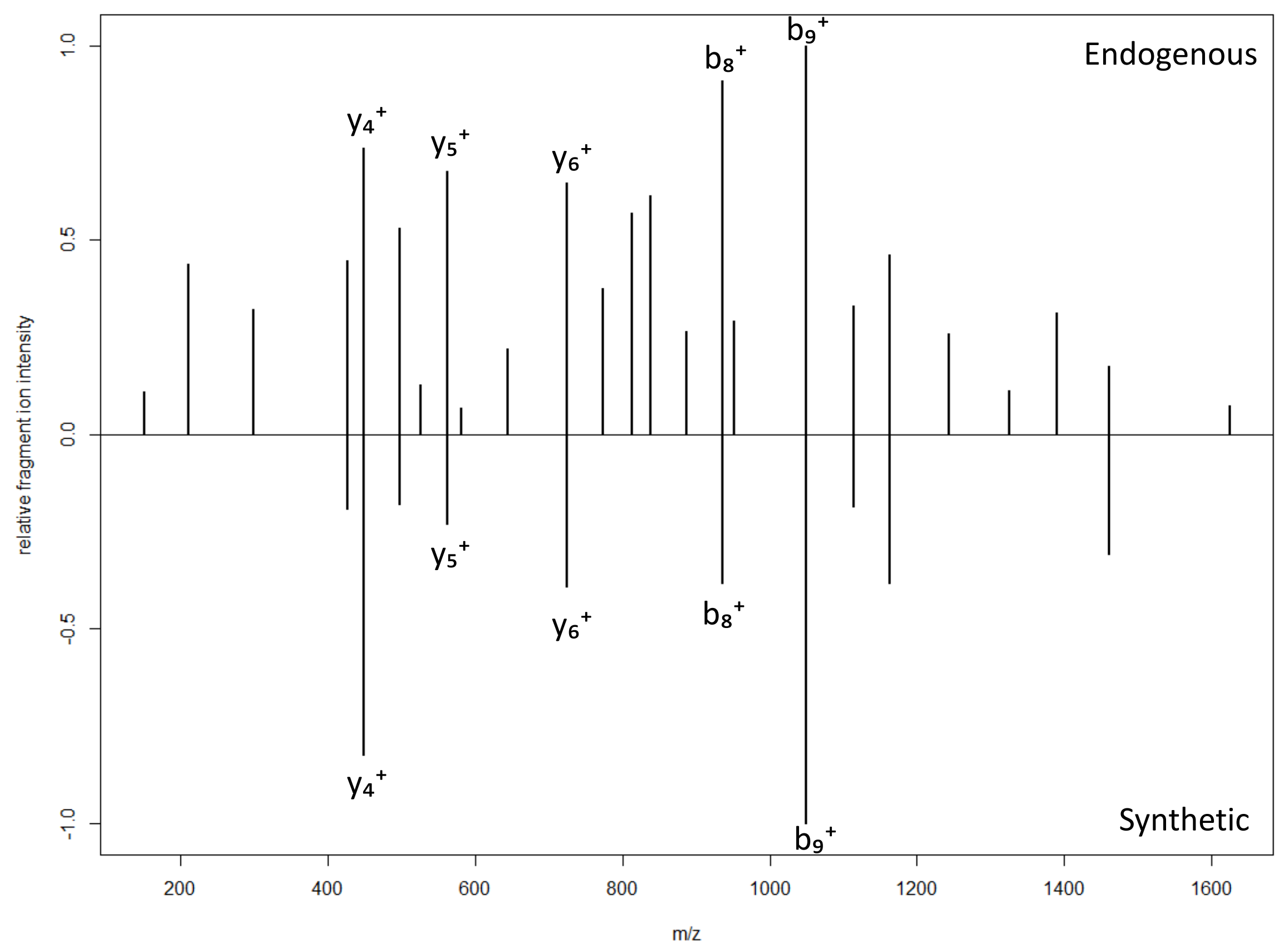



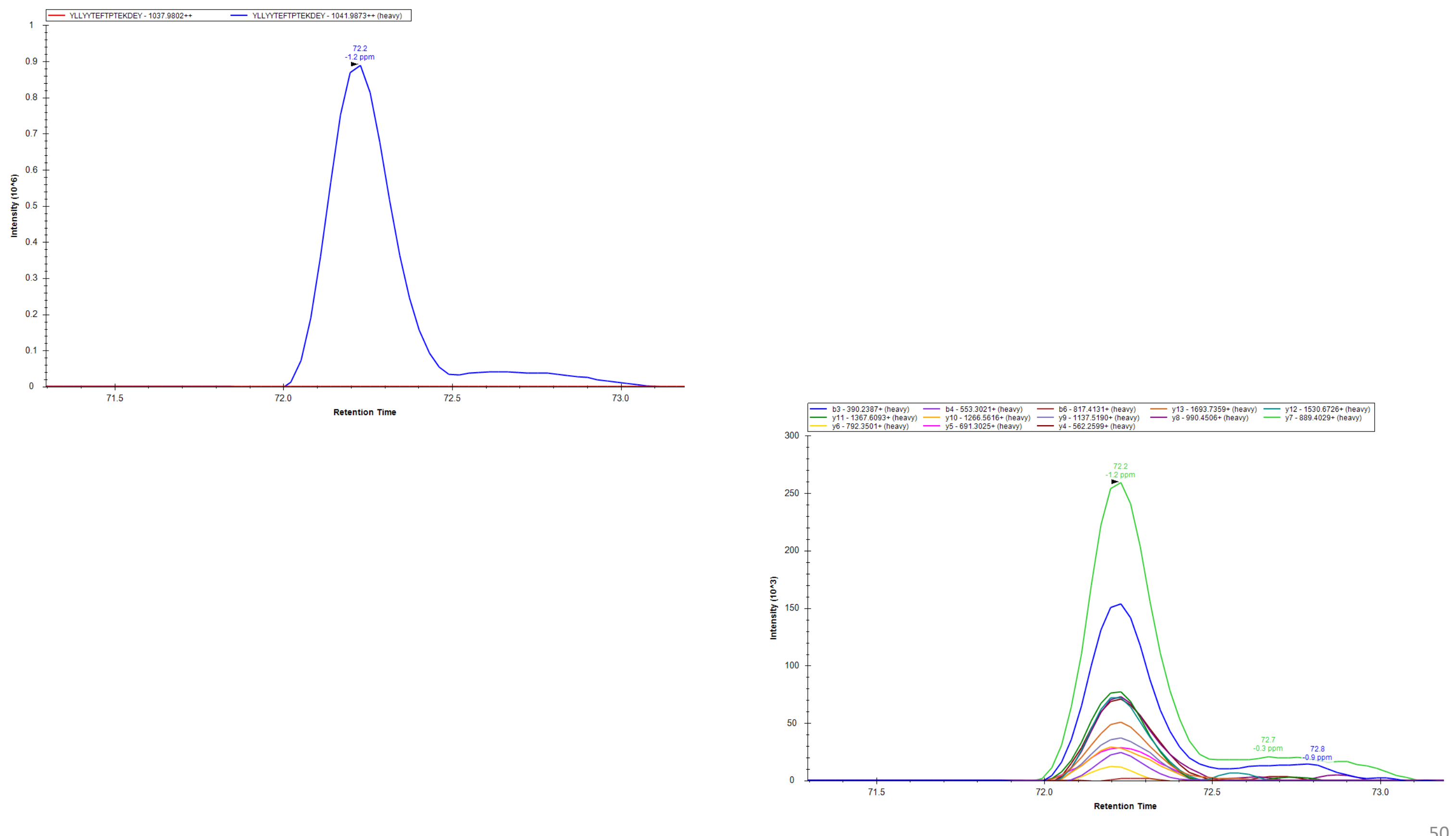


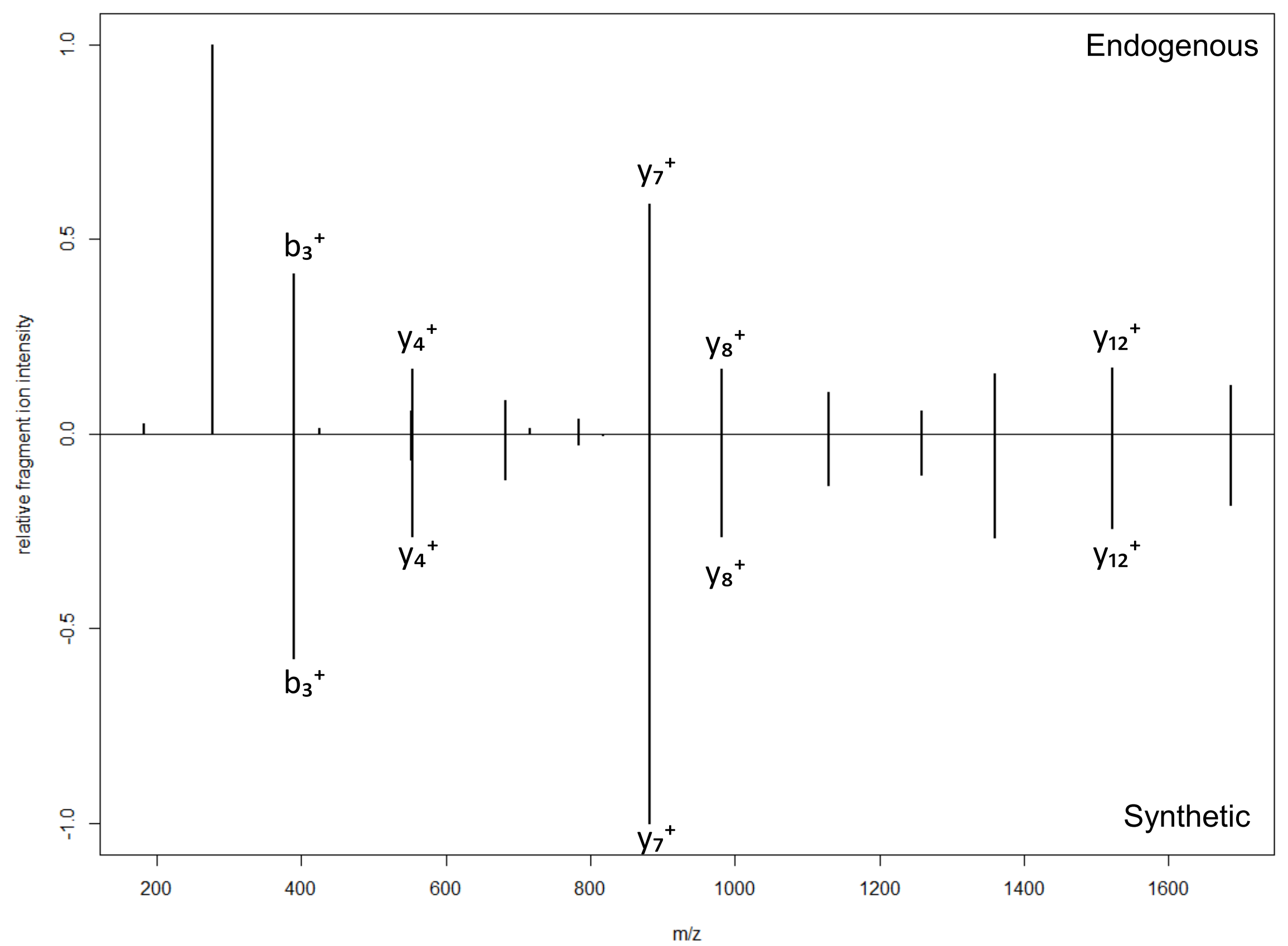










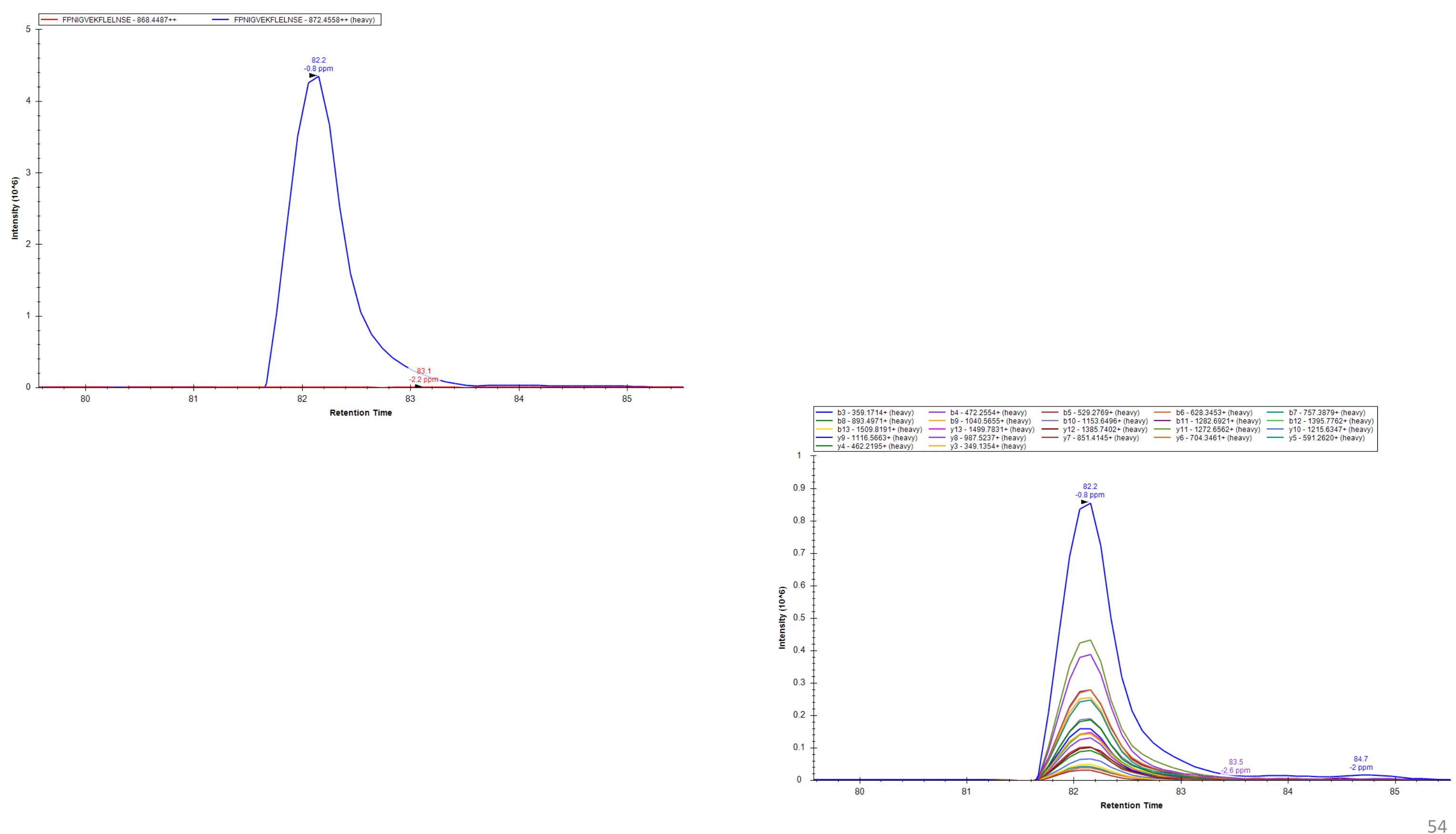


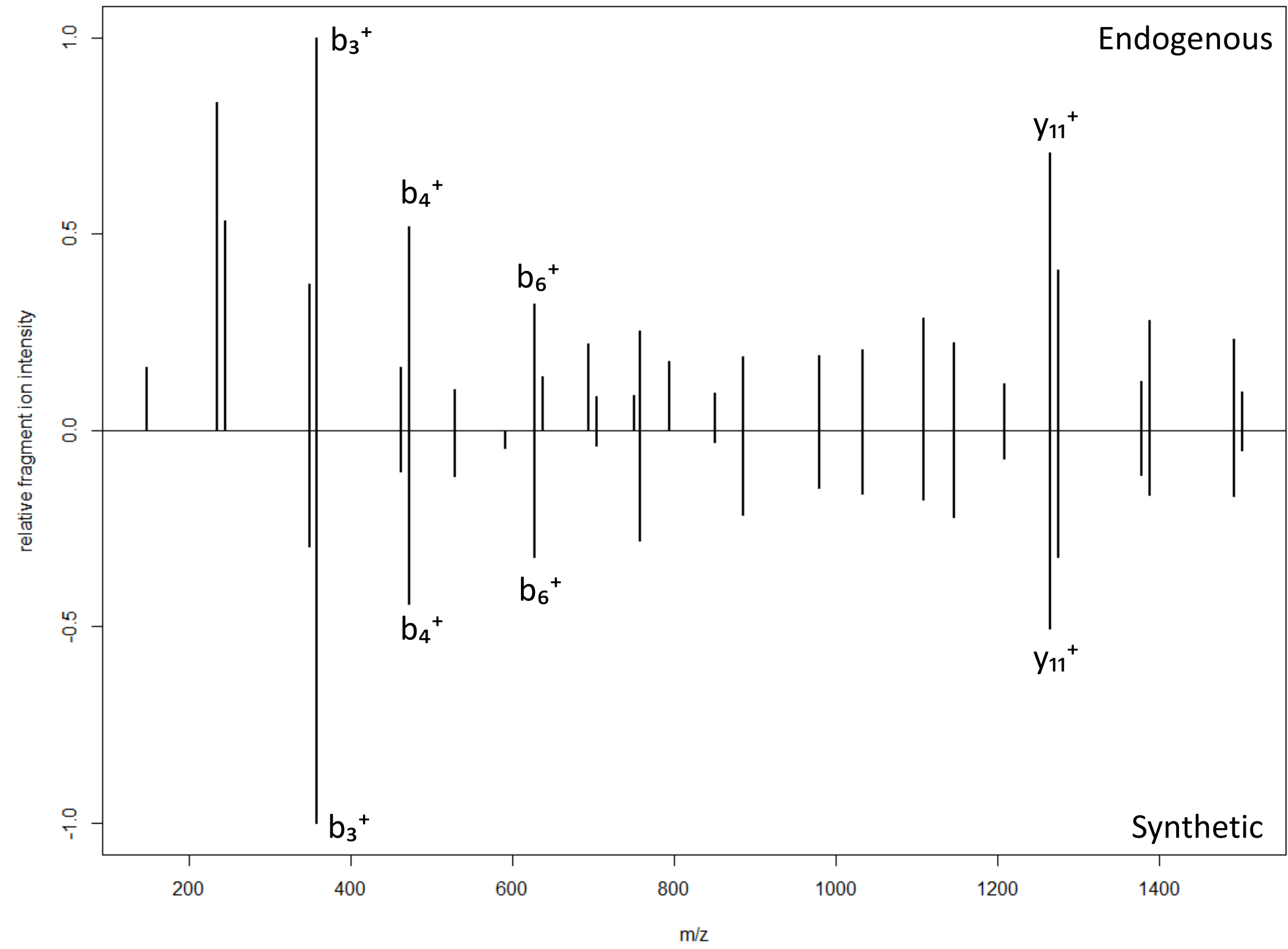



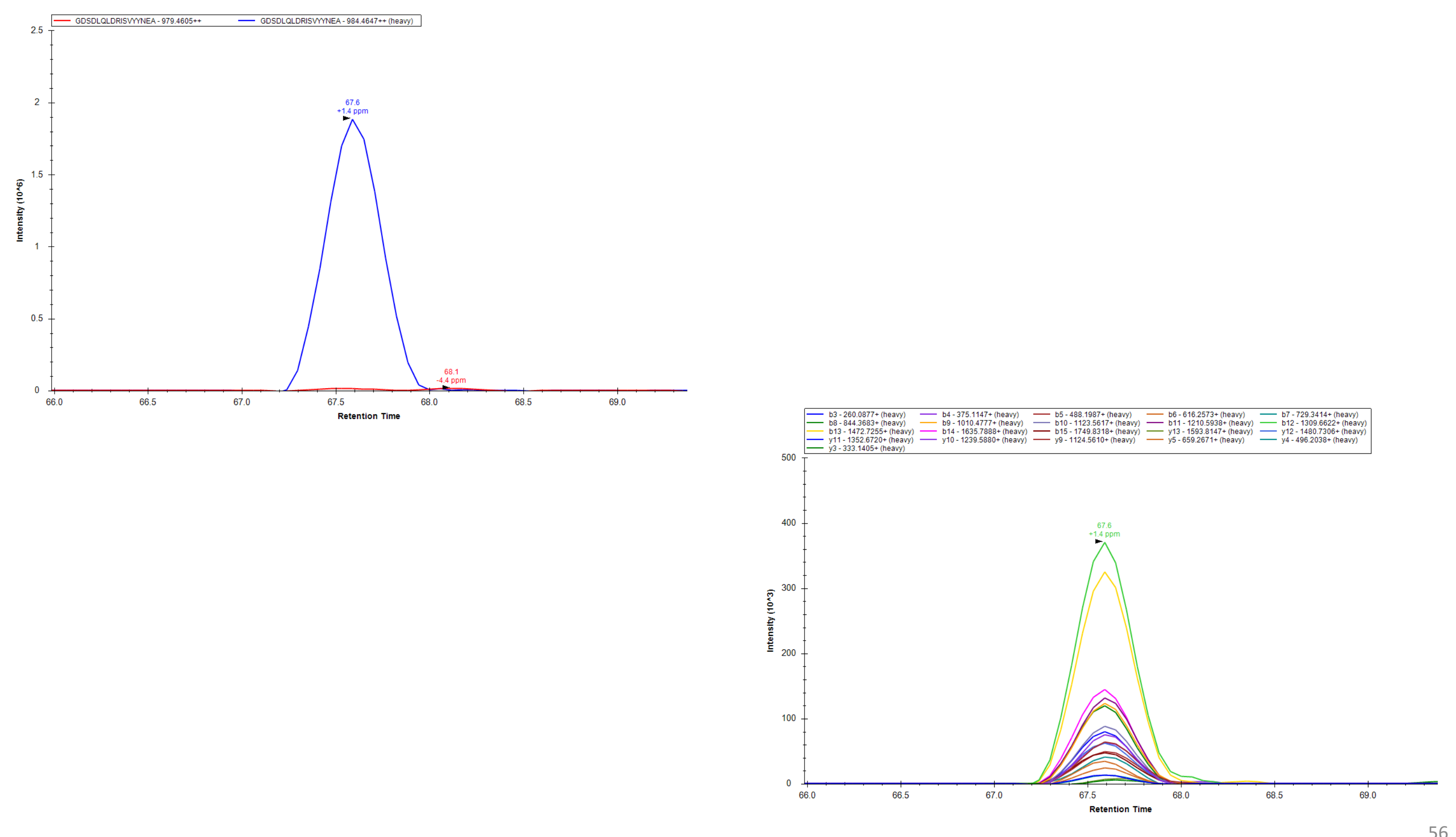


\section{GDSDLQLDRISVYYNEA}

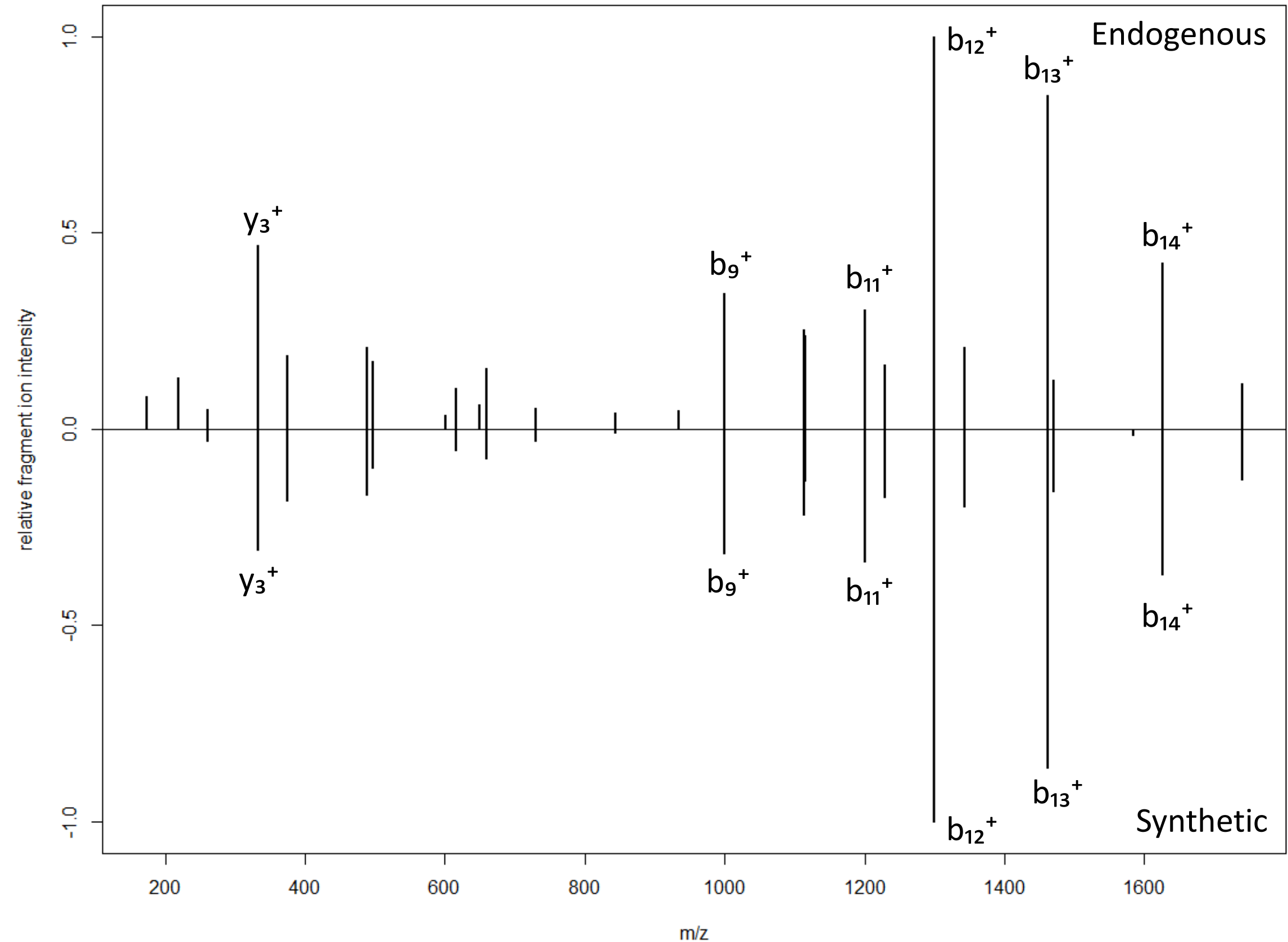



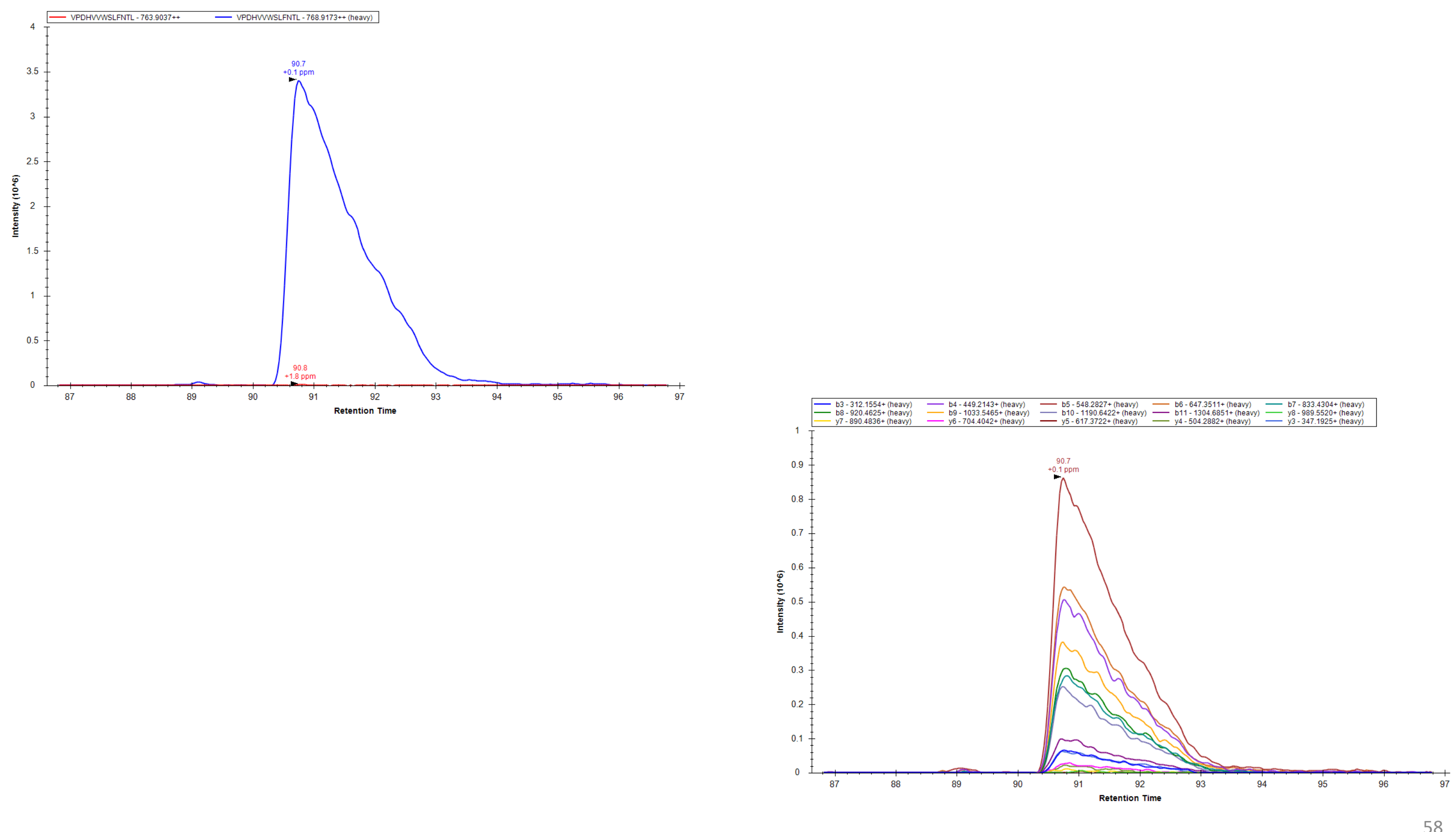
VPDHVVWSLFNTL

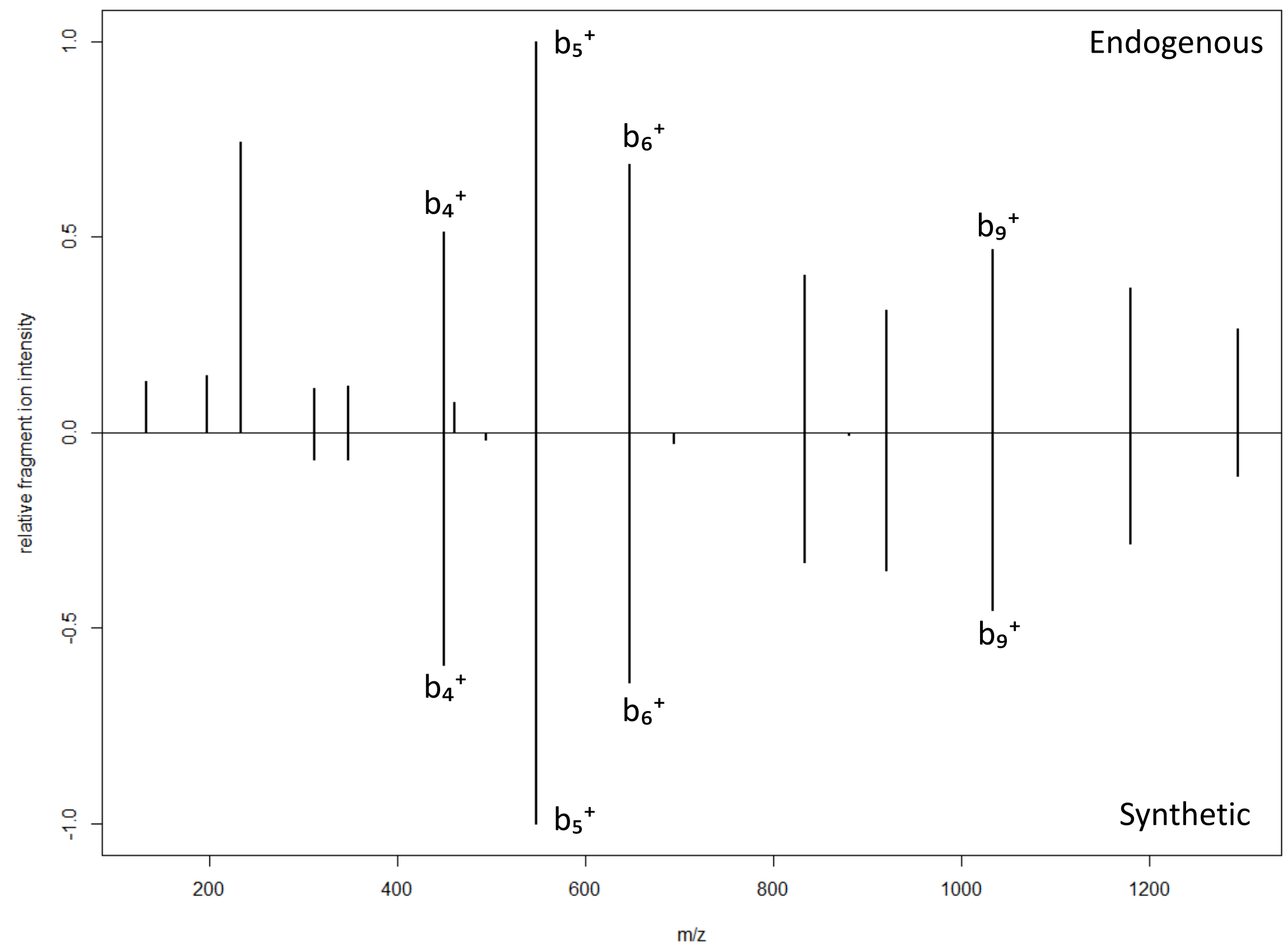






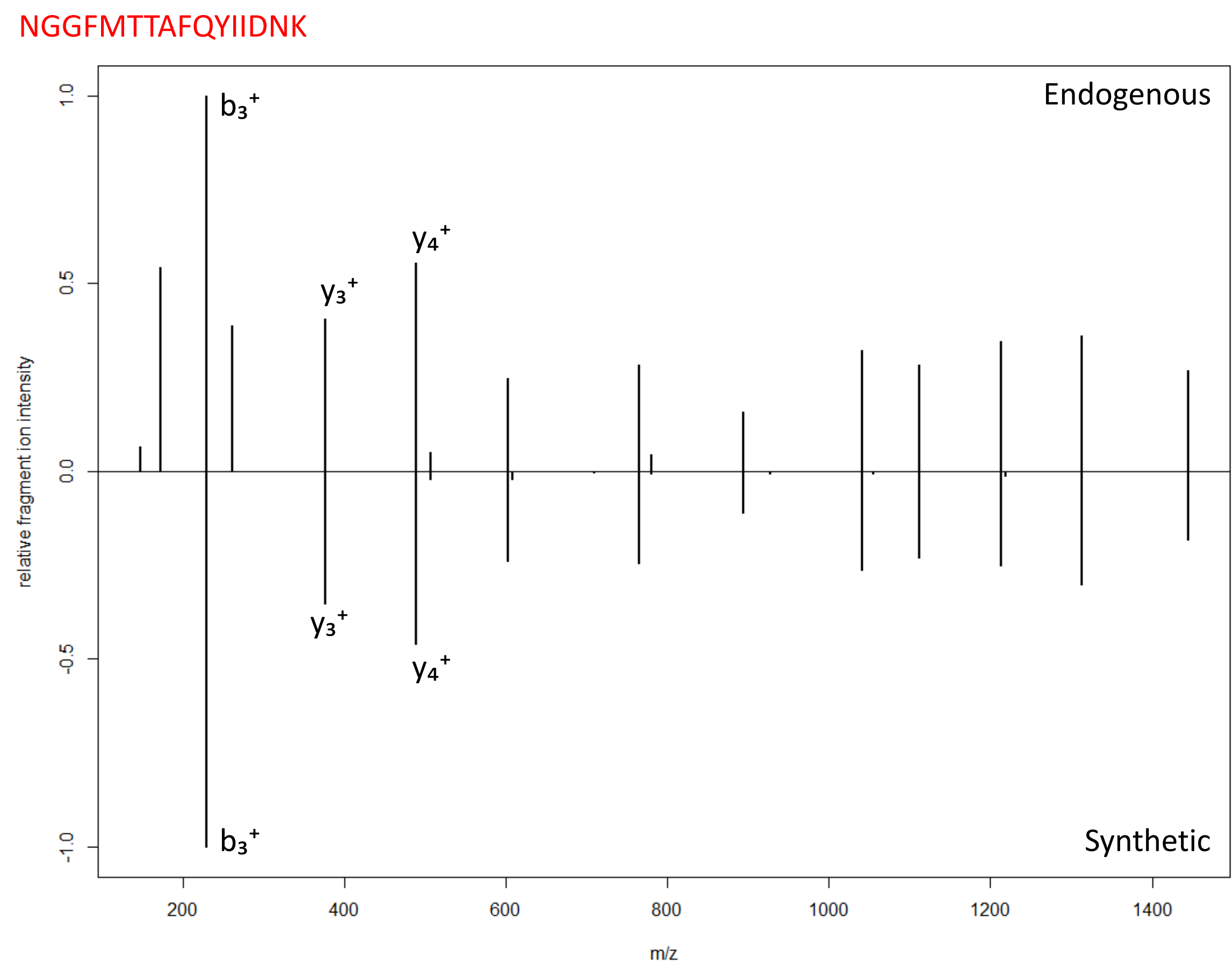



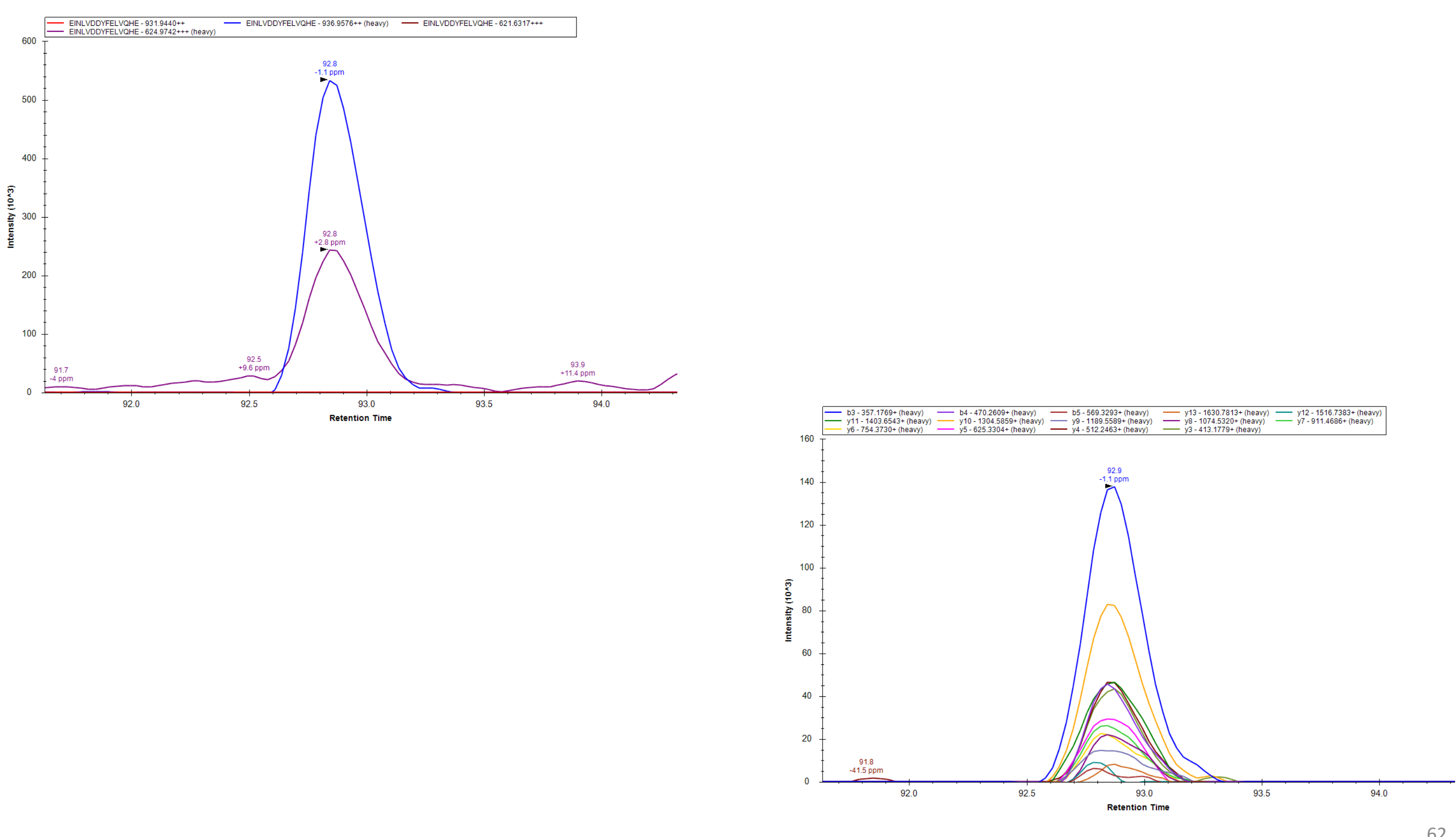
EINLVDDYFELVQHE

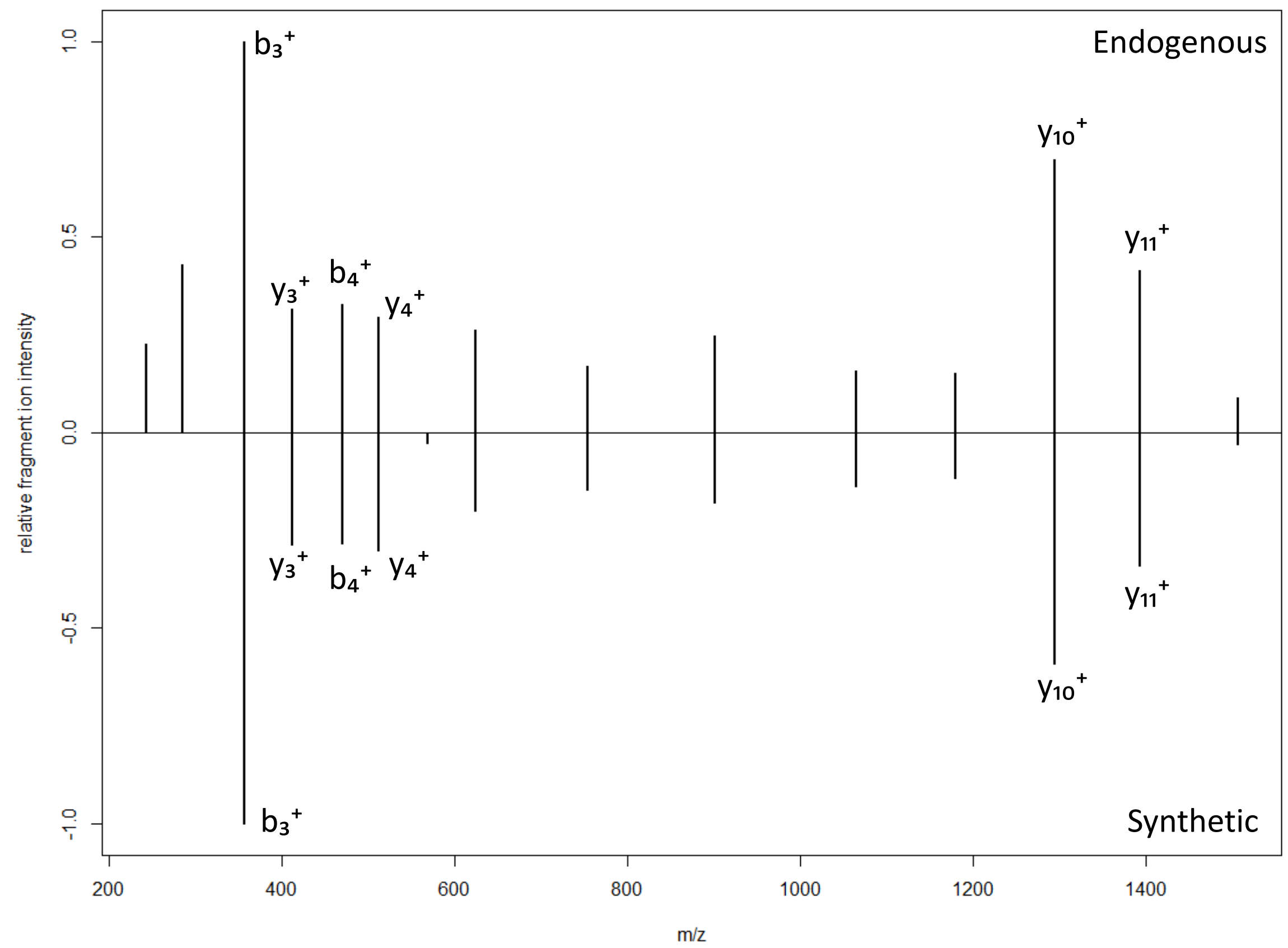



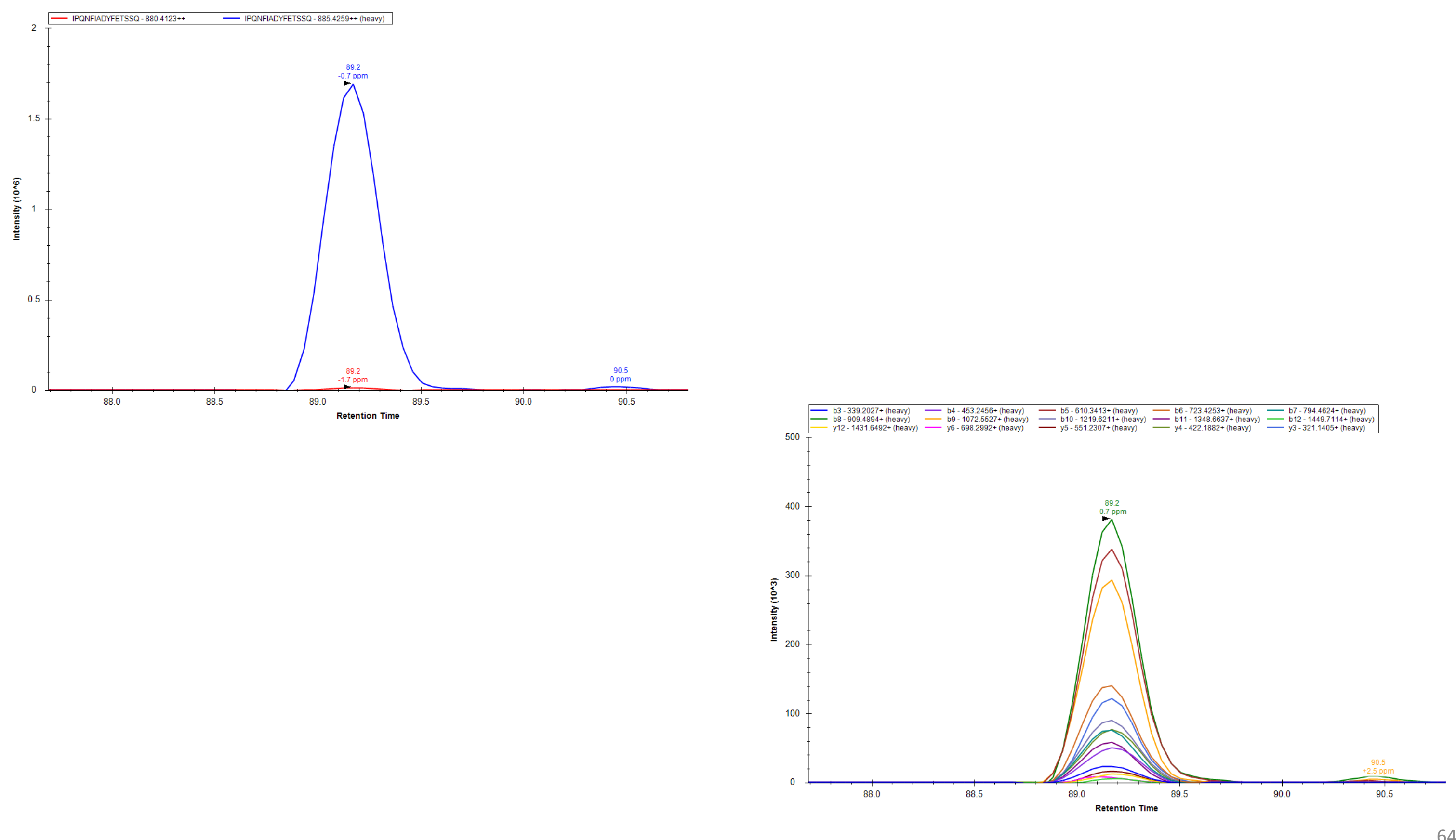


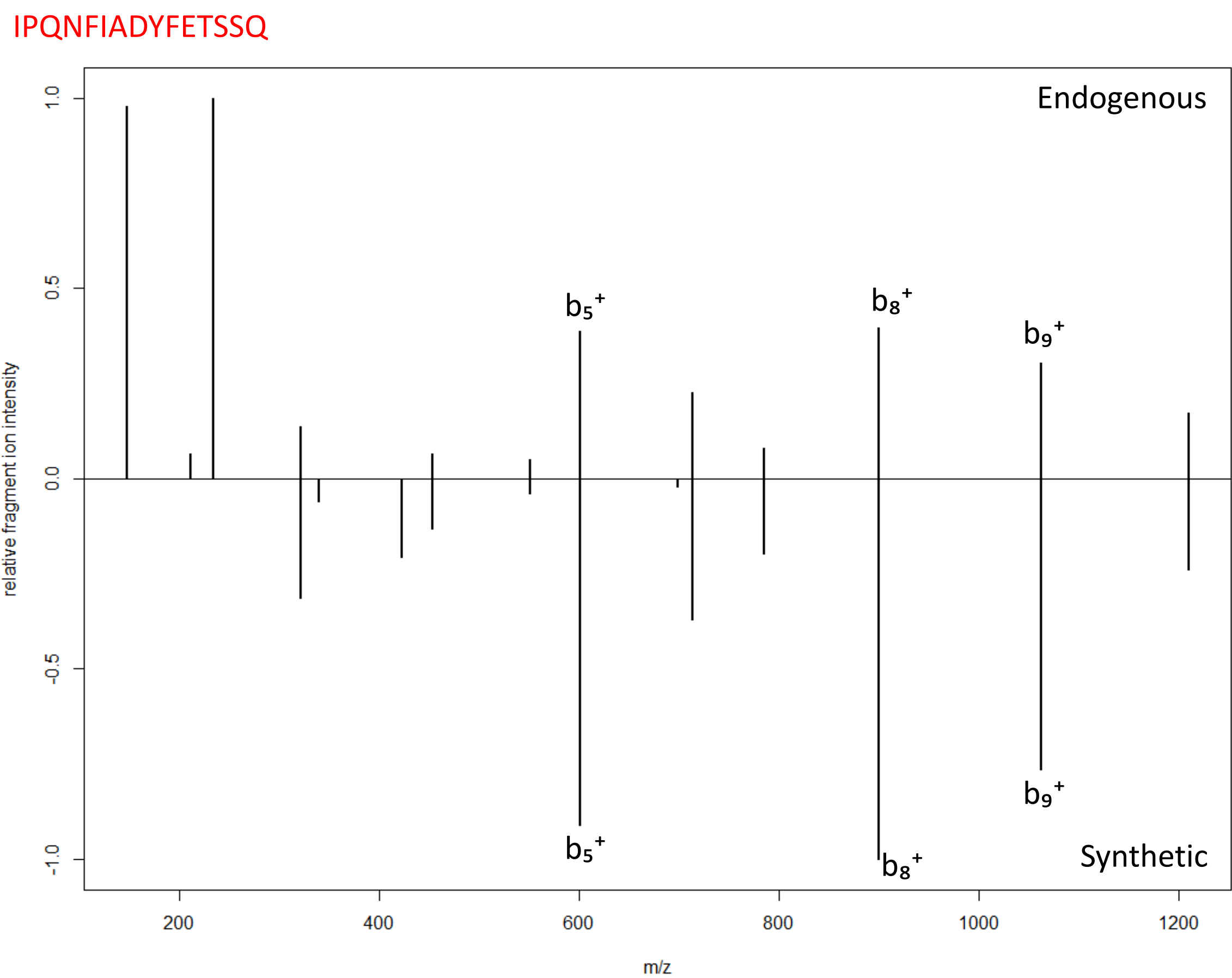



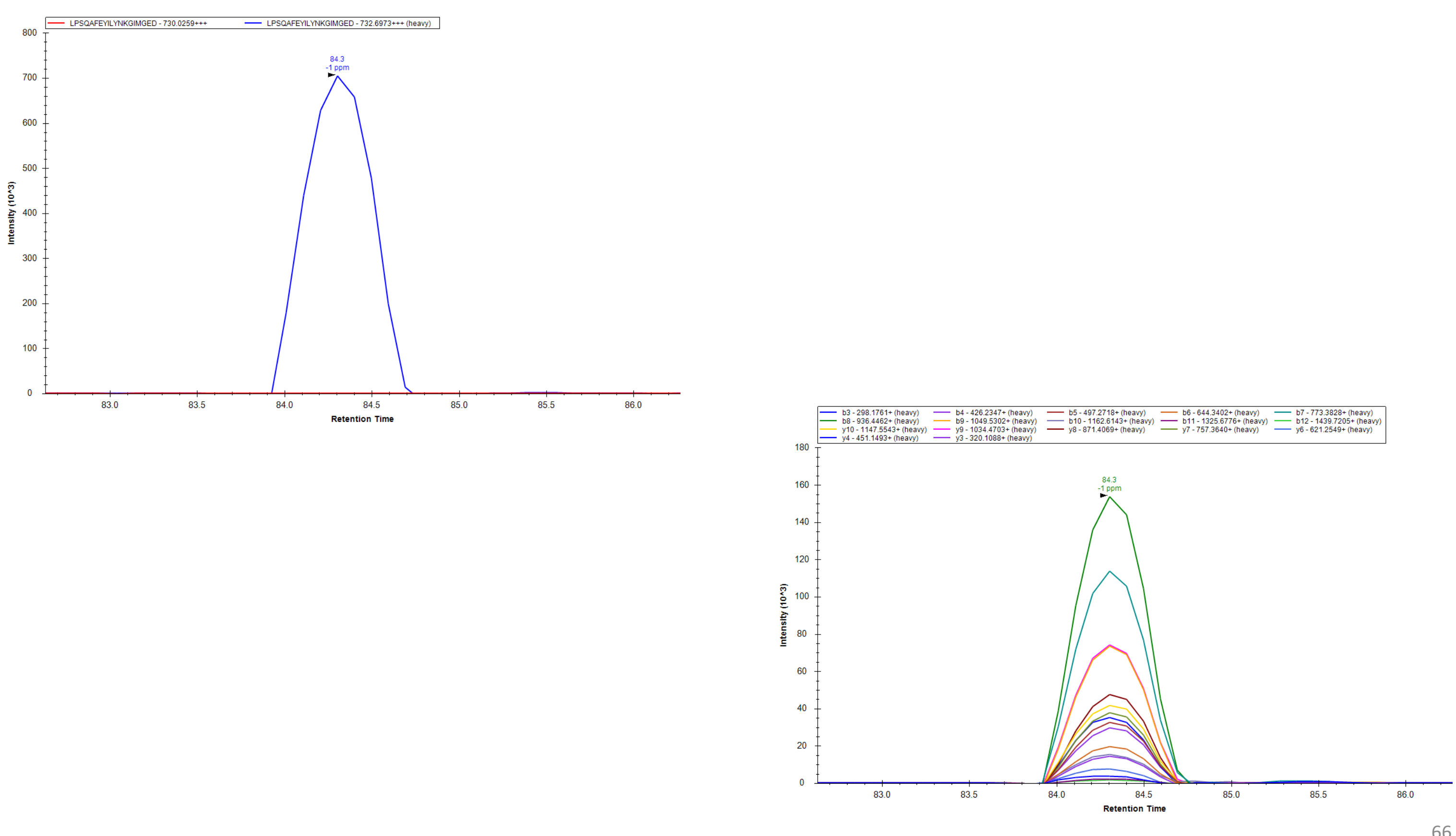


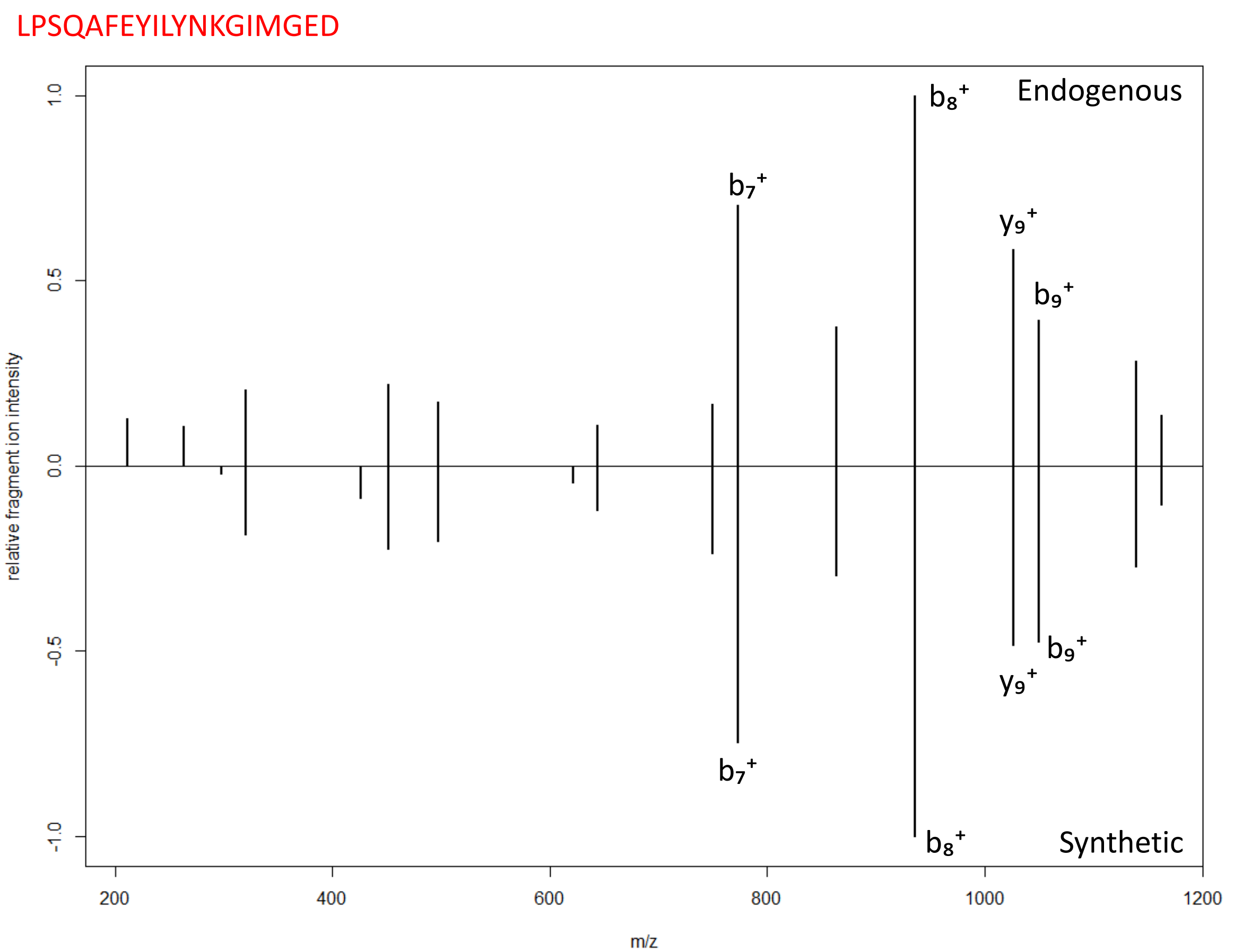


Fig. S9

\section{S9A}
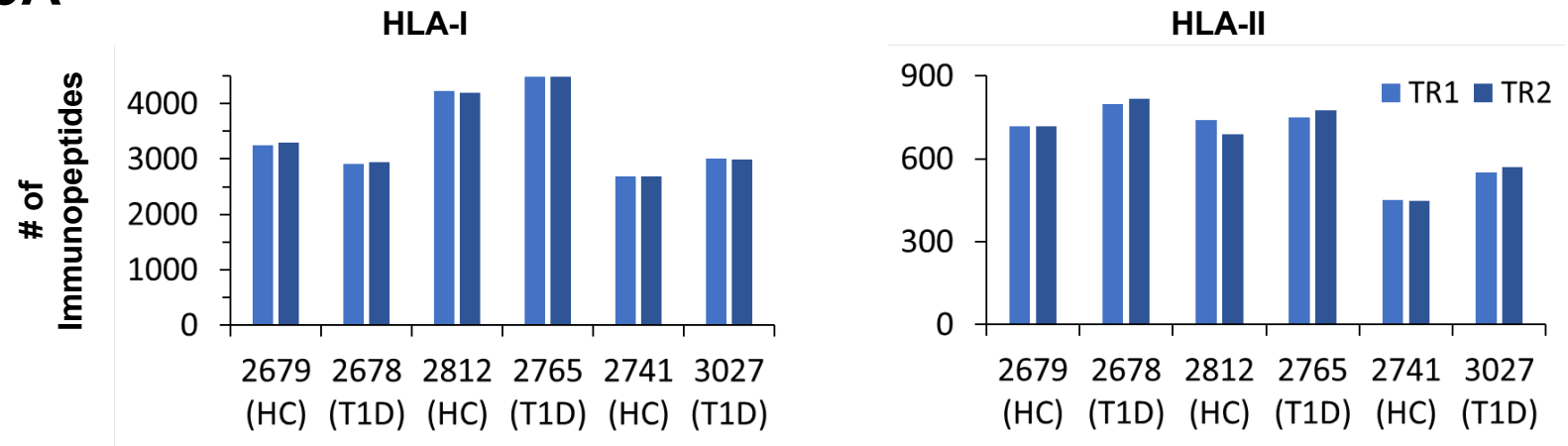

\section{S9B}

Fig. S10

\section{S10A}
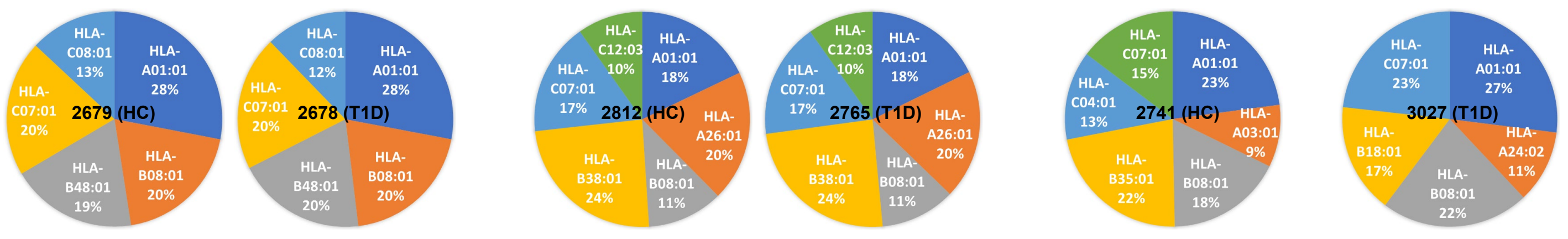

\section{S10B}
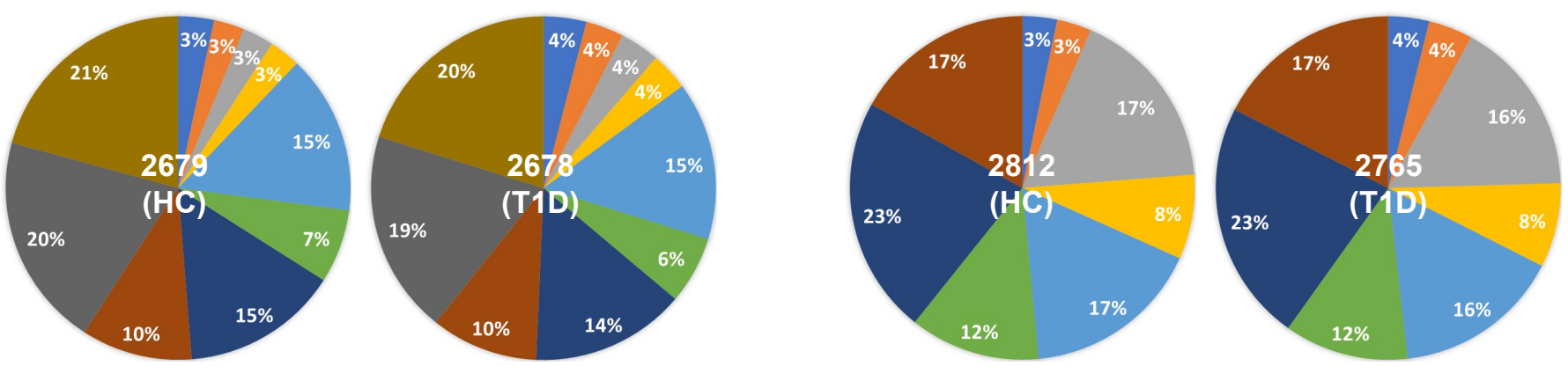

- HLA-DPA10103-DPB10401 - HLA-DPA10103-DPB11601 HLA-DQA10501-DQB10201 HLA-DQA10501-DQB10302

- HLA-DPA10201-DPB10101 HLA-DPA10201-DPB1040 - HLA-DQA10501-DPB10101 HLA-DPA10201-DPB10401 - HLA-DQA10301-DQB10201 HLA-DQA10301-DQB10302 - HLA-DQA10301-DQB10201 $=$ HLA-DQA10301-DQB10302 - DRB1_0301 - DRB1_0401



- HLA-DPA10103-DPB10401 HLA-DPA10103-DPB10402 HLA-DQA10101-DQB10201 - HLA-DQA10501-DQB10501 HLA-DQA10501-DQB10201 - DRB1_0101



HLA-DPA10103-DPB10101 - HLA-DPA10103-DPB10301 1- HLA-DPA10201-DPB10301 - HLA-DQA10501-DQB10201 - HLA-DQA10501-DQB10604 - HLA-DQA10102-DQB10201 - HLA-DQA10102-DQB10604 - DRB1_0301 
Fig. S11

Fig. $\$ 12$
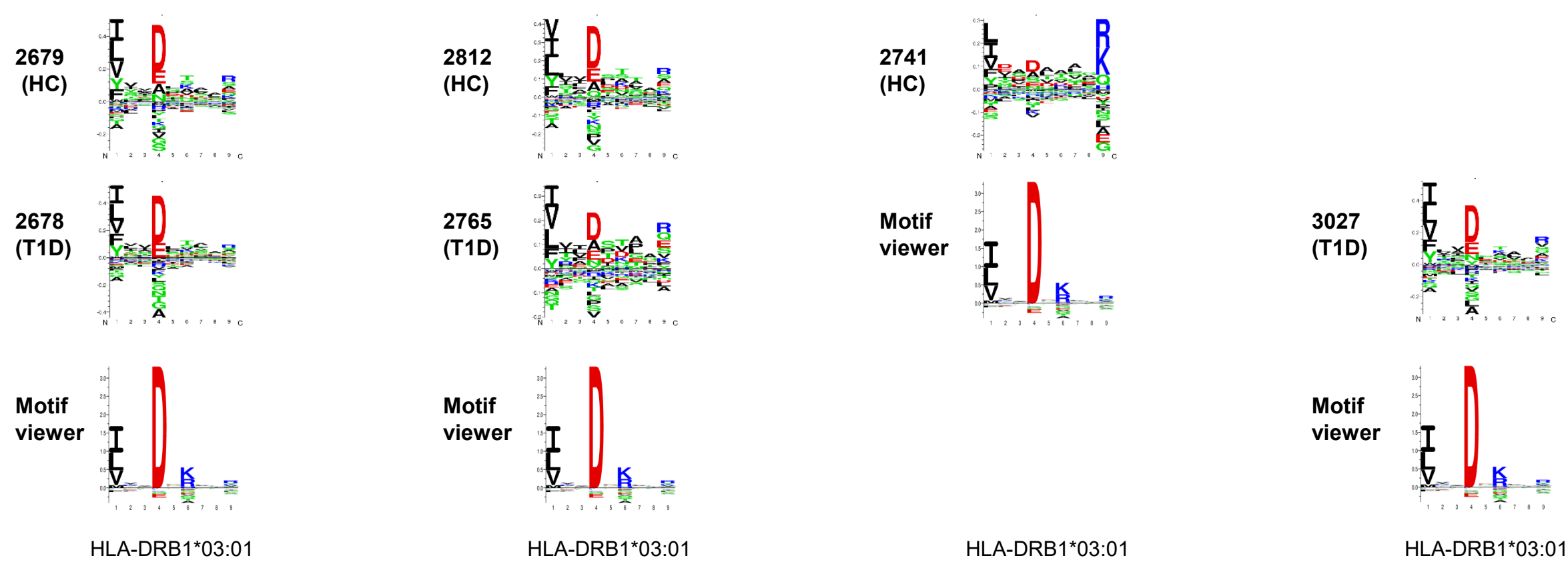

HLA-DRB 1 *03:01

HLA-DRB $1{ }^{*} 03: 01$

HLA-DRB1 ${ }^{* 03: 01}$

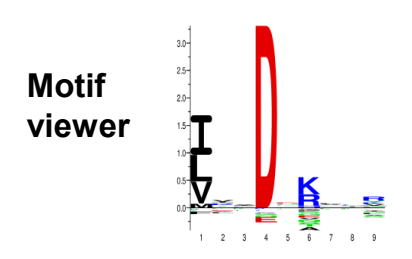

HLA-DRB ${ }^{*}$ 03:01 
Fig. $\mathbf{S 1 3}$

\begin{tabular}{|c|c|c|c|}
\hline \multicolumn{2}{|l|}{ This study } & \multicolumn{2}{|c|}{ IEDB } \\
\hline Immunopeptide sequence & Antigen & Linear epitope & MHC ligand assay \\
\hline
\end{tabular}

Identified during HLA-I immunopeptide enrichment

ETVWHLEEF

HLA-DPA1

QSEAGSHTLQWMY

HLA-B

Reported

Positive

Identified during HLA-II immunopeptide enrichment

AQGALANIAVDKANLE

DDTQFVRFDSDAASPREEPR

DDTQFVRFDSDAASPRGEP

DDTQFVRFDSDAASPRGEPR

DDTQFVRFDSDAASQKMEPR

HLA-B

HLA-C

DDTOFVRFDSDAASO

HLA-C

DDTOFVRDSDAASQRMEPR

HLA-A

HLA-A

LANIAVDKANLEIMT

LRSWTAADTAAQITQR

LRSWTAVDTAAQISEQ
TQFVRFDSDAASPRTEP

HLA-BRA

TQFVRFDSDAASPRTEP

A-B;HLA-C

TQFVRFDSDAASPRTEPR

HLA-E

HLA-B

HLA-B

VDDTQFVRFDSDAASQKMEPRAPW

HLA-A

Reported

Positive

HLA-A

Reported

Reported Positive

$\begin{array}{ll}\text { Reported Positive } & \\ \text { Reported } & \text { Positive }\end{array}$

Reported Positive

Reported

Reported

Positive

No information available

Positive

No information available

Reported

Reported

Reported

Reported

Positive

Reported

Reported

Positive

Positive

No information available

No information available 